\title{
El proyecto de vida y la retención de jóvenes talento en algunas provincias antioqueñas
}

\author{
Life project and retention young talents in some Antioquia Provinces
}

Recibido: 07-04-2020 • Aprobado: 09-11-2020 • Página inicial: 227 - Página final: 278

\author{
Ángel Emilio Muñoz Cardona* \\ Gustavo Adolfo Pherez Gómez**
}

Resumen: la finalidad del presente artículo de investigación es observar la relación: felicidad urbana versus retención de jóvenes talento, en 27 municipios antioqueños integrados bajo la figura de Provincias Administrativas y de Planificación (PAP). De allí, las preguntas de investigación: ¿qué tan felices son los jóvenes adolescentes de undécimo grado de las Provincias de Cartama, San Juan, Aguas y Magdalena Medio? ¿Cómo ven ellos la realización de sus proyectos de vida en sus municipios? ¿Qué satisfacción brinda a futuro el crecimiento económico y social de su municipio? La investigación se basa en los índices: Bienestar Pluridimensional, Felicidad Urbana y Felicidad Integral. La metodología de investigación se basó en entrevistas focales y la elaboración de 2.119 cuestionarios, con un nivel de confianza del $95 \%$ y un margen de error del 5\%. Cada cuestionario reunió 44 preguntas donde se hace una caracterización demográfica; se evalúa la satisfacción con los recursos y servicios municipales ofertados y las relaciones de pertinencia con la comunidad. El estudio concluye en la necesidad de una administración pública más comprometida con el fomento cultural de sus ciudadanos en el manejo y uso del tiempo libre, con inversiones públicas encaminadas a fortalecer la cohesión social o de apoyo mutuo ciudadano para el logro de un estar bien común e igual para todos.

Palabras clave: felicidad subjetiva; felicidad intersubjetiva; equipamiento de ciudad; proyecto de vida; autorrealización; emprendimiento.

\begin{abstract}
The purpose of this research essay is to observe the relationship: urban happiness versus retention of young talent, in 27 Antioquia municipalities integrated under the figure of Administrative and Planning Provinces (APP). From there, the research questions: how happy are the young eleventh grade adolescents from the Provinces of Cartama, San Juan, Waters and Magdalena Medio? How do they see the realization of their life projects in their municipalities? What satisfaction do they the economic and social growth of your municipality bring you in the future? The research is based on the indices: Multidimensional Wellbeing, Urban Happiness and Comprehensive Happiness. The research methodology was based on focal interviews and the elaboration of 2,119 questionnaires, with a confidence level of $95 \%$ and a margin of error of $5 \%$. Each questionnaire gathered 44 questions where a demographic characterization is made; Satisfaction with the Municipal Resources and Services Offered and Relevant Relations with the Community are evaluated. The study concludes on the need for a public administration more committed to the cultural promotion of its citizens in the management and use of free time, with public investments aimed at strengthening social cohesion or mutual citizen support for the achievement of a common good and equal for all citizens.
\end{abstract}

Keywords: Subjective happiness; intersubjective happiness; city equipment; life project; self-realization, entrepreneurship.

$$
\begin{array}{r}
\text { JEL: H41 - H52 - H53 - H54 - } \\
\text { I23 - I30 - O15 - P25 - R53 }
\end{array}
$$

\footnotetext{
* Economista de la Universidad de Antioquia, Especialista en Economía del Sector Público de la Universidad Autónoma Latinoamericana, Magíster en Filosofia Política y Ética de la Universidad de Antioquia, Doctor en Filosofía Civil de la Universidad Pontificia Bolivariana y PhD. en Economía Pública de la Vrije Universiteit Amsterdam. Director del Grupo de Investigación Gobierno, Territorio y Cultura y docente de planta de mérito nacional de la Escuela Superior de Administración Pública - ESAP, Antioquia.

angelemil@gmail.com - ORCID: https://orcid.org/0000-0001-5008-0983

** Licenciado en Educación, Especialista en Ministerio Pastoral de la Universidad Universidad Adventista de Colombia, Magíster en Educación de la Universidad Adventista de Chile y Doctor en Ciencias de la Educación de la Universidad Nacional del Rosario. gpherez@unac.edu.co - ORCID: https://orcid.org/0000-0002-6515-0240
} 


\section{O projeto de vida e a retenção de jovens talentos em algumas Províncias de Antioquia}

Resumo: ele objetivo deste ensaio de pesquisa é observar a relação: felicidade urbana $\mathrm{x}$ retenção de jovens talentos, em 27 municípios de Antioquia integrados na figura das Províncias Administrativas e Planejadoras (PAP). A partir daí, a pesquisa questiona: Quão felizes estão os jovens adolescentes do $11^{\circ}$ ano das Províncias de Cartama, San Juan, Águas e Magdalena Medio? Como eles vêem a realização de seus projetos de vida em seus municípios? Que satisfação o crescimento econômico e social do seu município traz para você no futuro? A pesquisa é baseada nos índices: Bem-estar Pluridimensional, Felicidade Urbana e Felicidade Integral. A metodologia da pesquisa baseou-se em entrevistas focais e na elaboração de 2.119 questionários, com nível de confiança de $95 \%$ e margem de erro de 5\%. Cada questionário reuniu 44 questões onde é feita uma caracterização demográfica; São avaliadas a satisfação com os recursos e serviços municipais oferecidos e as relações relevantes com a comunidade. $\mathrm{O}$ estudo conclui sobre a necessidade de uma administração pública mais comprometida com a promoção cultural de seus cidadãos na gestão e uso do tempo livre, com investimentos públicos voltados para o fortalecimento da coesão social ou apoio mútuo cidadão para a realização de um bem comum e o mesmo para todos.

Palavras-chave: felicidade subjetiva; felicidade intersubjetiva; facilidades da cidade; projeto de vida; autorrealização; empreendedorismo. 


\section{Introducción}

Afirma el psicólogo David McClelland que el emprendimiento está asociado a los impulsos de las necesidades de independencia del individuo y logro de sus metas personales (1989), lo que Maslow llama la autorrealización (2008), o lo que más claramente la filosofía del liberalismo económico de Mill (2005) llama libertad de autodeterminación, o lo que Nussbaum y Sen (1998) reconocen como función de las capacidades para el logro individual de mejores niveles de calidad de vida. Desde esta perspectiva, afirman Muñoz y Martínez (2020) que los impulsos de McClelland crean un individuo racional egoísta, pero a su vez solidario, es decir, un ser social que impulsado por la búsqueda de satisfacer deseos individuales de bienestar y felicidad, también está motivado por la necesidad ontológica de satisfacer deseos sociales y brindar solución a necesidades públicas comunes, esto es, un ser interesado en el reconocimiento social, tal y como lo planteaba Smith (1997), 20 años antes de la Riqueza de las Naciones.

Desde una racionalización propia de las economías de mercado en la que se incentiva la búsqueda de la libertad del individuo para la satisfacción de sus necesidades, nace desde el 2001, con Hawkins, la era de las economías creativas o naranja (Buitrago y Duque, 2013), la cual ve el emprendimiento como resultado de la capacidad natural propia a todo ser humano: creación e innovación, incluso en las poblaciones más pobres y de bajos niveles de formación; lo que se convierte en un factor estratégico para el mejoramiento de la calidad de vida en economías en vías de desarrollo y con altas poblaciones de migración joven. Esta ha sido una estrategia del gobierno colombiano, a través de la Ley 1014 de 2006, para mejorar el desarrollo local y territorial, es decir, cerrar las brechas de las desigualdades territoriales a partir de la formación, tanto del adolescente de secundaria como del joven profesional:

[1]a educación debe incorporar, en su formación teórica y práctica, lo más avanzado de la ciencia y de la técnica, para que el estudiante esté en capacidad de crear su propia empresa, adaptarse a las nuevas tecnologías y al avance de la ciencia, de igual manera debe actuar como emprendedor desde su puesto de trabajo (Congreso de la República de Colombia, Ley 1014 de 2006).

Además, el Estado busca a través de la Constitución Política estimular la capacidad de emprendimiento de los trabajadores urbanos, campesinos, profesionales, estudiantes, organizaciones sociales y comunitarias dentro de los 


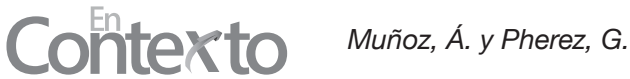

límites del bien común. Un ejemplo son los artículos 64, 304, 333 (Constitución Política de Colombia, 2012); Lo que para el 2020 hace parte del Plan Nacional de Desarrollo (2019), Pacto por Colombia, pacto por la equidad, el gobierno propone tres principios o ejes de desarrollo local.

El emprendimiento asociado a la búsqueda de la felicidad individual y social en cuanto factor de desarrollo económico es impulsado a través de políticas públicas y programas de gobierno. Es decir, a través de políticas de distribución del gasto, en instituciones tales como: Ruta N, Maloca, Parque Explora e InnovAntioquia (2019), los cuales son motivadores del emprendimiento a través de los Proyectos de Vida, lo que se ha convertido en los últimos años en un instrumento pedagógico en los colegios con undécimo grado. Es un instrumento de crecimiento económico y de fidelización del joven a su municipio; esto último implica que el joven adolescente se siente satisfecho con su localidad, porque ve en ella su futuro, es feliz tanto desde lo individual como desde los social viviendo allí.

Ante la discusión no científica de si existe o no la felicidad y si es posible medirla, los autores clásicos de la economía como Smith (1997), Bentham y Mill (Troyer, 2003) y más recientemente la escuela del utilitarismo con Guisán (2004), Acemoglu y Robinson (2012) ven en la felicidad general de los ciudadanos de los países una suerte de buenas políticas de distribución económica, de gobiernos menos corruptos y transparentes. De allí que el estudio del concepto de felicidad se ha dividido en dos corrientes: la felicidad subjetiva, propia de la satisfacción individual y la felicidad intersubjetiva, propia de las relaciones de conjunto (Harari, 2018, pp.42-47).

La felicidad subjetiva da a entender la valoración individual que cada consumidor da al disfrute de bienes que demanda, valoración microeconómica que puede cambiar con los estados de ánimo o de riqueza de la persona en concreto, como lo hace el índice de felicidad de Pemberton (Beytía y Calvo, 2011). Para el historiador Harari, la felicidad subjetiva "es algo que existe en función de la conciencia y creencia de un único individuo y desaparece o cambia si este individuo concreto cambia sus creencias" (2015, p. 136; 2018, p.47). Asimismo, la felicidad intersubjetiva da cuenta de: las relaciones sociales propias de los Estados sociales de derecho, la capacidad de conciliación, establecer acuerdos, asociación para la consecución del bien común e investigación con fines sociales. Como afirma Harari: "Lo intersubjetivo es algo que existe en el seno de la red de comunicación que conecta la conciencia subjetiva de muchos individuos" (2015, p.136). Desde esta perspectiva, aparecen aportes muy importantes de 
economistas contemporáneos como Stiglitz et al. (2015), incluso de filósofos morales como Nussbaum y Sen (1998), Martha Nussbaum (2010) y François Dubet (2017).

Si el bienestar de la población, es decir, si la felicidad general nace de las inversiones públicas, entonces la hipótesis de investigación parte de creer que "existe una relación positiva entre el emprendimiento y la felicidad urbana como realización de los proyectos de vida y de las capacidades" (McClelland, 1989). Para investigadores de la felicidad como Guisán (2004), Harari (2015), Stiglitz et al. (2015), existe una correlación positiva entre capacidades humanas y felicidad, las cuales se han visto reflejadas en la disminución de enfermedades y aumentos de las edades promedios de vida, por ejemplo, la medicina moderna ha logrado reducir en los últimos doscientos años la mortalidad infantil del 33\% a menos del 5\% (Harari, 2015, p.414).

Otros investigadores de la escuela latinoamericana de la filosofía de la liberación ven en la correlación de las variables capacidades humanas y felicidad una relación negativa; una apuesta egoísta de poder en la que naciones y comunidades más fuertes buscan someter a otras, expropiándola de sus riquezas naturales (Dussel, 1998). Conciben el desarrollo y el subdesarrollo como una colonización, es decir, como un saqueo de las riquezas mineras y de hidrocarburos. Riquezas de explotación productiva que hacen más felices a ciudadanos de pocos países que a miles de millones de ciudadanos de otras naciones que lo pierden todo, incluso hasta las esperanzas de un futuro mejor o de unas posibilidades de vida mejor, tal y como lo afirman Muñoz et al. (2020). Sin embargo, dichas relaciones de la política económica internacional que profundizan en las brechas sociales de desarrollo y subdesarrollo económico hacen posible medir la felicidad, tal y como lo afirman Rey (2015) y Kaplan (2017).

\section{Indicadores de felicidad urbana utilizados en el estudio de las PAP}

El concepto de felicidad general es asociado a la satisfacción de condiciones de vida digna, por lo menos, dentro de las sociedades contemporáneas. Entre las 16 variables que incluyen los estudios de felicidad general se tienen: salud con calidad, educación con calidad, diversidad ambiental, nivel o costo de vida gobernanza y transparencia, bienestar de la población, uso del tiempo libre, movilidad y seguridad, vitalidad comunitaria e inclusión social, cultura, nivel de ingresos, desempleo y empleo, satisfacción con la vida o proyecto de vida, necesidades básicas insatisfechas, esperanza de vida y el precio de la propiedad. 


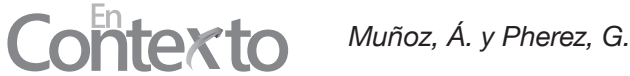

Mientras el Producto Interno Bruto (PIB) evalúa cuatro variables de crecimiento de la producción: consumo, gasto público, exportaciones netas e inversión. El Índice de Bienestar Pluridimensional de Amartya Sen, Joseph Stiglitz y Jean Paul Fitoussi propuesto en el 2015, evalúa 10 categorías, las cuales son: las condiciones de vida materiales -ingreso, consumo y riqueza-, salud con calidad, educación como formadora de capacidades reales, uso del tiempo libre o de ocio, calidad del trabajo, participación en la vida política, gobernanza, relaciones sociales entre vecinos, medio ambiente (tanto a presente como a futuro) y la seguridad laboral y del hábitat o del entorno (Stiglitz et al., 2015).

El Índice de Bienestar Pluridimensional se centra en los mejoramientos de las condiciones de vida y de vida buena de la población, esto es, acceso a bienes públicos fundamentales, condiciones del hábitat o de relación con los vecinos, de las oportunidades de autorrealización y de satisfacción con el gobierno, la transparencia de las instituciones públicas. Factores que en sí mismos reducen las externalidades negativas sobre el bien común y los fenómenos asociados a las migraciones o voto con los pies (Muñoz, 2019c, pp.240-247).

La ONU a través de la resolución (A/RES/65/309) establece que el indicador de crecimiento del PIB no refleja la felicidad y el bienestar de las personas de un país, ni tampoco el desarrollo sostenible, la erradicación de la pobreza, la felicidad y el bienestar de todos los pueblos, por lo que recomienda, a todos los países miembros, en aras del cumplimiento de los Objetivos de Desarrollo del Milenio:

1.La elaboración de nuevos indicadores de felicidad social, como objetivo y aspiración universal. Es la manifestación del espíritu de los Objetivos de Desarrollo del Milenio.

2.Entender la importancia de la búsqueda de la felicidad general y el bienestar social como guía del desarrollo económico de las naciones y de sus políticas públicas.

3.La búsqueda de la felicidad personal es un objetivo humano fundamental, es decir, es un derecho inalienable y un deber obligatorio de los gobiernos procurarlo.

4.Reconocer con beneplácito el ofrecimiento de reflexión sobre la felicidad interna bruta FIB alcanzado por el país de Bhután.

De allí que la República de Colombia, como país miembro de la ONU, adopte bajo la ley 1583 del 30 de octubre de 2012 la resolución de la ONU A/RES/65/309, aprobada en los Estados Unidos el 25 de agosto de 2011, bajo el título: $L a$ felicidad: hacia un enfoque holístico para el desarrollo. A partir de allí, en la 
historia de la economía colombiana, el Departamento Nacional de Estadística (DANE) realizó en agosto del 2016 la primera encuesta sobre la felicidad de orden nacional, Índice de Felicidad Nacional (IFN), a 9,710 personas en las cuatro ciudades más grandes del país: Cali, Medellín, Barranquilla y Bogotá. La encuesta mide un conjunto de cuatro variables: felicidad, satisfacción, preocupación y depresión (DANE, 2016).

Desde el 2018, el grupo de investigación Gobierno, Territorio y Cultura de la Escuela Superior de Administración Pública de Antioquia calcula el Índice de Felicidad Urbana (IFU). El IFU evalúa el bienestar de la población joven universitaria de último semestre, en las ciudades del área metropolitana del Valle de Aburrá, Manizales, Pereira y Quindío y de la población joven adolescente de las Provincias Administrativas y de Planificación del territorio PAP. El Instrumento de encuesta comprende tres variables y 44 categorías. El conjunto de las tres variables es: caracterización sociodemográfica, satisfacción con los recursos y de pertenencia a la comunidad. El estudio de felicidad urbana parte de la hipótesis:

A mayor migración de la población joven de un municipio por falta de oportunidades para la autorrealización menores son las posibilidades de desarrollo y crecimiento del municipio. Por el contrario, a menor migración de la población joven de un municipio por abundantes oportunidades para la autorrealización mayores son las posibilidades de desarrollo y crecimiento del municipio y sus localidades (Muñoz, 2018; 2019a).

A partir del 2016, la ciudad núcleo del Valle de Aburrá evalúa la felicidad subjetiva de los medellinenses con el Índice de Felicidad Integral (IFI), el cual comprende ocho variables y 22 categorías. Ellas son:

1. Vida: en ella se miden estándares de calidad de vida, satisfacción con la vida, experiencias emocionales, usos del tiempo libre e igualdad de oportunidades.

2.Experiencia de Felicidad: se mide las experiencias de felicidad sentidas por la ciudadanía y la distribución de la felicidad en términos de la equidad del gasto público.

3.Entorno: participación cultural y deportiva, satisfacción con la oferta pública inmobiliaria o de equipamiento de ciudad, recursos naturales y espacio público.

4.Salud: estado de salud y actividades saludables de la población, bienestar psicológico y valoración del sistema de salud por la ciudadanía. 


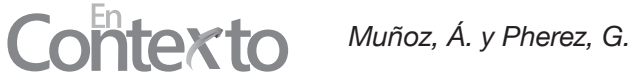

1.Seguridad y convivencia: percepción ciudadana de la seguridad, victimización y convivencia.

2.Educación: asistencia escolar y pertinencia de la educación.

3. Buen gobierno y ciudadanía activa: participación ciudadana, gobernanza, libertad de expresión, libertad de opinión y confianza en el gobierno.

4.Movilidad urbana: valoración de la movilidad peatonal y de vehículos (Plan de Desarrollo de Medellín, 2016).

El Índice de Felicidad Integral (IFI) de Medellín se basa en el indicador de felicidad de Pemberton Happiness Index, el cual posee dos componentes de medida: un referido al bienestar social en términos del disfrute de bienes materiales y el otro, a la suma de experiencias positivas y negativas vividas. Pero a diferencia del IFI, el Pemberton Happiness Index toma en cuenta la cultura.

El IFI de Medellín como el Índice de Felicidad Urbana (IFU) de la ESAP de Antioquia evalúan el bienestar social en términos del disfrute de bienes comunes, y la satisfacción con las instituciones democráticas como forjadoras de bienestar futuro. Es decir, evalúan la vitalidad comunitaria: el altruismo o trabajo solidario para el logro del bienestar comunal (Muñoz y Quintero, 2020; Muñoz y Martínez, 2020). De allí, la importancia que para la Organización de las Naciones Unidas (ONU) reviste el día internacional de la felicidad no como día festivo, sino de reflexión social sobre los logros alcanzados en el bienestar social de las personas a partir de las acciones de los gobiernos (Resolución A/ $\mathrm{RES} / 66 / 281)$.

Entre las características de los colombianos más felices, el IFN del DANE encontró: está entre jóvenes de 26 y los 35 años de edad, tiene pareja estable, es trabajador formal, puede ahorrar, es optimista sobre el futuro, lee al menos un libro al año, tiene postgrado, tiene internet, es hombre, vive en zona urbana, vive en Medellín, está pagando su casa. Resultados de felicidad que van muy acordes con los hallados por el IFI de la ciudad de Medellín, aplicados a 511 personas (Plan de desarrollo de Medellín, 2016; Redacción 2017) y por el IFU de la ESAP de Antioquia, aplicados a 4250 universitarios de último semestre (Muñoz, 2019a; 2019b; Muñoz y Martínez, 2020; Muñoz y Quintero, 2020). 


\section{Tres diferencias fundamentales entre la Provincia y el Área Metropolitana}

Afirma la politóloga de la Universidad de Antioquia Olga Lucia Zapata (2017) que los cambios electorales surgidos con la elección popular de alcaldes en 1988 y de gobernadores en 1991 (Congreso de la República de Colombia, Acto Legislativo 01 de 1986) fueron el inicio de nuevas formas de hacer la democracia en el país, las cuales han seguido fortaleciéndose con: la Ley 152 de 1994 que ordena la elaboración de Planes de Desarrollo y la Ley Orgánica de Ordenamiento Territorial 1454 de 2011 (Senado de la República de Colombia, 1994); ambas permiten la integración departamental y municipal para una mejor planeación del territorio y de las condiciones de vida de sus habitantes. ${ }^{1}$ Sin embargo, dichos cambios administrativos para la planeación del territorio han sido poco usados en el país. Antioquia puede ser la excepción al tener un área metropolitana bien configurada $\mathrm{y}$, al menos, tres Provincias que intentan integrarse política y socialmente desde lo fiscal. De allí que la politóloga afirme:

[c]on la entrada en vigencia de la Ley 1454 de 2011 se esperaba un incremento de ésta y otras figuras de cooperación e integración regional, ya que apela a los principios de: regionalización que promueve la creación de las Regiones de Planeación y Gestión y las Regiones Administrativas y de Planificación con miras a fortalecer la unidad nacional; solidaridad y equidad territorial, que fomentan las relaciones multinivel basadas en la cooperación; y asociatividad que estimula la asociación entre entidades territoriales (Zapata, 2017, p.3).

Sin embargo, una primera diferencia entre las Provincias y el área metropolitana inicia a partir del 2011, cuando en la conformación de las Provincias se limitó la integración, casi exclusivamente, a las cercanías geográficas y, sobre todo, a la protección de los recursos naturales, lo que se convierte en una visión estratégica para la salvaguardar a estos y el hábitat en los municipios que se integran; no obstante, deja de lado, los fortalecimientos de la integración financiera. Las áreas metropolitanas, por el contrario, parten de la existencia de ciudades con alta densidad poblacional que gozan de un relativo desarrollo comercial, empresarial y tienen la necesidad de fortalecer la protección

Esfuerzos y cambios administrativos en la planificación administrativa del territorio que viene desde 1968 con el Acto Legislativo 01 de 1968, Artículo 63, 1 Ley 1 de 1975 y el Decreto 1390 de 1976. Así mismo, la Constitución Política estable la cooperación y unión municipal como estrategia de desarrollo conjunto en los artículos: 289, 306, 319 y 321. 


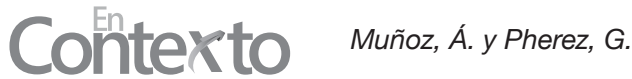

ambiental, comercial e industrial a partir de una ciudad núcleo, es decir, del ejemplo alcanzado por la ciudad de mayor desarrollo.

Una segunda diferencia entre las áreas metropolitanas y las Provincias está en el tiempo de conformación y de consolidación; mientras las áreas metropolitanas llevan más de 23 años de experiencia y de facilidades de recursos, las Provincias llevan menos de 4 años y tienden a disolverse, porque adolecen de recursos apropiados para la inversión conjunta, lo que no garantiza la sostenibilidad de dicha conformación. ${ }^{2}$ La norma establece que los municipios que se asocian en provincia deben contar con recursos propios que puedan aportar y tener el $0,2 \%$ del impuesto predial, ya que no pueden generar cargos al presupuesto general de la nación ni al sistema general de participación ni a las regalías. En otras palabras, si la conformación de una provincia es entre municipios de quinta y sexta categoría, los cuales representan el $90 \%$, es decir, son pobres, dicha asociación no logra las economías de escala en sus inversiones por falta de presupuesto. Esto no facilitaría el mejoramiento institucional en la planeación del territorio y de la calidad de vida de sus habitantes (Chamorro, 2012).

La tercera sería que, en las áreas metropolitanas, la ciudad núcleo tiende a permanecer más en el tiempo. En las Provincias, el municipio líder puede rotar más fácil en el tiempo, lo que puede ser más una desventaja que una ventaja, ya que da lugar a la politización de los mecanismos de selección de la ciudad núcleo, a la confrontación política. Siempre es mejor contar con el liderazgo municipal de las localidades con mayor experiencia política y de organización económica. Sin embargo, para el exgerente del Área Metropolitana del Valle de Aburrá, Prieto (2017), las Provincias son un esquema asociativo de planeación territorial, una forma de gestionar servicios públicos, realizar proyectos comunes de regalías y de gestión ambiental. Las Provincias son las herramientas reales de descentralización y autonomía administrativa; son la mejor forma de unión política para lograr el crecimiento económico local y conservar la inversión realizada por los diferentes municipios en la población joven, democratizar con equidad el desarrollo territorial y alcanzar mejores índices de felicidad o de bienestar general.

En Julio de 2016 se creó la Provincia de Cartama integrada por 11 municipios del suroeste antioqueño. Dicha asociación se creó con el fin de aprovechar el asentamiento de la Fábrica de Licores en la región, los megaproyectos de desarrollo vial programados en la región y la creación de la micro central hidroeléctrica. 


\section{Metodología aplicada al caso de estudio de las PAP}

Si se parte de la hipótesis: existe una relación positiva entre el emprendimiento y la felicidad urbana como realización de los proyectos de vida y de las capacidades, tal y como lo plantean McClelland, (1989), Nussbaum y Sen (1998); entonces, desde una prospectiva de felicidad urbana con desarrollo social, o de un bienestar ciudadano con la ciudad a través del logro generalizado de los proyectos de vida, nacen las preguntas de investigación: ¿qué tan felices son los jóvenes adolescentes de undécimo grado de las Provincias de Cartama, San Juan, Aguas y Magdalena Medio? ¿Cómo ven ellos la realización de sus proyectos de vida en sus municipios? ¿Qué satisfacción brinda a futuro el crecimiento económico y social de su municipio?

Para demostrar dicha hipótesis y dar solución a las preguntas de investigación se realizaron, primero, siete entrevistas focales en caminadas a descubrir cuáles eran las potencialidades de emprendimiento ofrecidas por la localidad a estudiantes de undécimo grado de las Provincias en siete municipios de mayor número de estudiantes: Santa Barbara, Puerto Nare, El Peñol, Ciudad Bolívar, Andes, Alejandría y Caramanta. Segundo, se realizaron 2.119 encuestas a jóvenes-adolescentes de último año de la secundaria de los principales colegios locales de los 27 municipios que integran las PAP estudiadas.

Si bien, en el 30\% de los municipios estudiados existe algún establecimiento universitario, no se encuestó población universitaria, con el fin de mantener homogeneidad muestral de estudio, los datos fueron analizados bajo el método estadístico multivariado, en otras palabras, del estudio de correlación de varias variables capaces de contribuir a la demostración de un resultado. En otras palabras, como variables aparentemente independientes: el equipamiento de ciudad, calidad del gobierno local y niveles de satisfacción con la seguridad coadyuvan a la explicación sobre las expectativas de logro de los proyectos de vida en jóvenes adolescentes; esto es, a la retención de jóvenes talento y a la felicidad urbana. La muestra estadística tomada posee un alfa del $95 \%$ de confianza y un margen de error del $5 \%$.

En cuestionarios de investigaciones sobre felicidad urbana y emprendimiento realizados durante los años 2018 y el 2019 (Muñoz, 2018; 2019a; 2019b; Muñoz y Martínez, 2020), se evaluaron: los equipamientos de ciudad, en términos de Jacobs (2011), la calidad de vida, las necesidades básicas insatisfechas y los proyectos de vida de los jóvenes-adolescentes de último año escolar, tal y como lo expresa Maslow (2008), Gehl (2010), Guisán (2004), Stiglitz et al. (2015). 


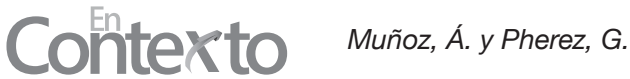

Si bien el IFU está conformado por 44 categorías, solo se tomaron aquellas que ayudan a responder las preguntas de investigación. El ensayo analizó la variable proyectos de vida en relación con: uso del tiempo libre, satisfacción de los adolescentes con la clase política, la administración pública y equipamiento de ciudad. Niveles de satisfacción que coadyuvan a las expectativas poblacionales sobre el crecimiento económico y bienestar futuro en las Provincias de Cartama, San Juan, Aguas, Bosques y Turismo; y tres municipios del Magdalena Medio: Puerto Nare, Puerto Berrío y Puerto Triunfo.

Hechas las anteriores claridades sobre los conceptos de felicidad urbana, Provincias y áreas metropolitanas pasemos a indagar sobre la satisfacción de los jóvenes-adolescentes de último año escolar de las Provincias de: San Juan; Cartama; Aguas, Bosques y Turismo y del Magdalena Medio antioqueño con su municipalidad, es decir, con el gobierno, la infraestructura de ciudad, la policía, la clase política y el progreso económico de la región.

\section{Breve caracterización de las provincias}

Las Provincias Administrativas y de Planificación del territorio y la conservación de los recursos naturales (PAP) iniciaron en Antioquia en el 2018, estas buscan convertirse en un nuevo modelo de gerencia pública capaz de mejorar la integración intermunicipal y la inversión pública territorial. Otras razones principales por la cual se conformaron fueron: la planificación conjunta del territorio; la protección conjunta del medio ambiente y de los recursos hídricos; reducir las migraciones de jóvenes calificados por la falta de oportunidades; reducir los fenómenos de conurbación y la aglomeración de las ciudades del Valle de Aburrá.

Este nuevo modelo de unión administrativa pública o de gerencia administrativa conjunta tiene como finalidad dar solución a las necesidades sociales comunes, por el bien de todos los ciudadanos que las integran, es decir, mejorar la inversión pública y privada en todos los municipios que conforman la unión; así como el empleo y las condiciones de vida digna de toda la población (salud, educación, en saneamiento básico y, sobre todo, en transparencia administrativa de los ingresos públicos). Entre las Provincias a analizar se tienen las de San Juan; Aguas, Bosques y Turismo; Cartama y Magdalena Medio.

La Provincia de San Juan está integrada por los municipios de Andes, Jardín, Hispania y Ciudad Bolívar de vocación cafetera, ganadera y turística. El municipio de Jardín es uno de los municipios de mayor atractivo turístico por 
su belleza paisajística, cafetera y ancestral. Fue conformada de acuerdo con el plan de ordenamiento territorial Ley 1454 de 2011 (Congreso de la República de Colombia, 2011; Zapata, 2017) y tiene como fin la protección de la cuenca del Rio San Juan, por lo que sus habitantes e instituciones políticas buscan conservar y preservar dicho afluente hídrico de las explotaciones mineras, del deterioro por contaminación productiva y heces humanas. Los municipios de la Provincia de San Juan poseen una densidad poblacional de 80.000 habitantes. En esta Provincia se realizaron 513 encuestas a jóvenes-adolescentes de undécimo grado en las seis principales instituciones de educación secundaria y se hicieron dos entrevistas focales en dos municipios a 20 estudiantes.

Provincia de Aguas, Bosques y Turismo conformada por los municipios de Alejandría, Cocorná, El Peñol, Granada, Guatapé, Marinilla, San Carlos, San Luís y San Rafael. Estos tres últimos municipios fueron epicentro de violencia en los años 80 por grupos al margen de la ley. La vereda El Orejón del municipio de San Carlos fue la primera localidad piloto del programa de paz para el desminado en Colombia a finales del 2017, y fue, a su vez, una de las primeras veredas en repoblamiento. La principal fuente económica de estos municipios es agrícola, ganadero, comercial, turismo y de energía eléctrica, en este último renglón, principalmente los municipios de Guatapé, San Rafael y El Peñol. Poseen una densidad poblacional de 160.700 habitantes aproximadamente. En la Provincia de Aguas se realizaron 581 encuestas a jóvenes adolescentes de undécimo grado en las nueve principales instituciones de educación secundaria y se hicieron dos entrevistas focales en dos municipios a 20 estudiantes.

Provincia de Cartama está integrada por los municipios de Caramanta, Fredonia, Jericó, La Pintada, Montebello, Pueblorrico, Santa Barbara, Támesis, Tarso, Valparaíso y Venecia. Municipios de vocación agrícola, cafetera, ganadera y leve explotación minera, con gran desarrollo turístico por sus bellezas naturales como religiosas. De los atractivos más relevantes está el Cerro de la Tusa y el municipio natal de la Santa Madre Laura. Poseen una densidad poblacional de 220.000 habitantes aproximadamente. En la Provincia de Cartama se realizaron 672 encuestas a jóvenes adolescentes de undécimo grado en las 12 principales instituciones de educación secundaria y se hicieron dos entrevistas focales en dos municipios a 20 estudiantes.

El Magdalena Medio de Antioquia está conformado por los municipios de Caracolí, Puerto Berrío, Puerto Nare, Puerto Triunfo, Maceo y Yondó. Los últimos cuatro son rivereños al río Magdalena, de vocación ganadera, pesquera, minera y turística. Dentro de la actividad económica del Magdalena Medio 


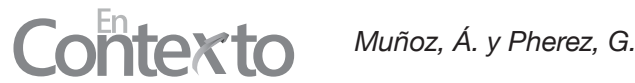

se destacan actividades como la minería de carbón, oro, cuarzo, mármoles, extracción de petróleo, cultivo de palma de aceite, ganadería extensiva y la pecuaria. La participación de la subregión en el PIB del departamento es del 3,3\% y posee una densidad poblacional de 100.000 habitantes. En el Magdalena Medio se realizaron 353 encuestas a jóvenes adolescentes de undécimo grado de las principales cuatro instituciones de educación secundaria de los municipios de Puerto Berrío, Puerto Nare y Puerto Triunfo y se hizo una entrevista focal en un municipio a diez estudiantes. 


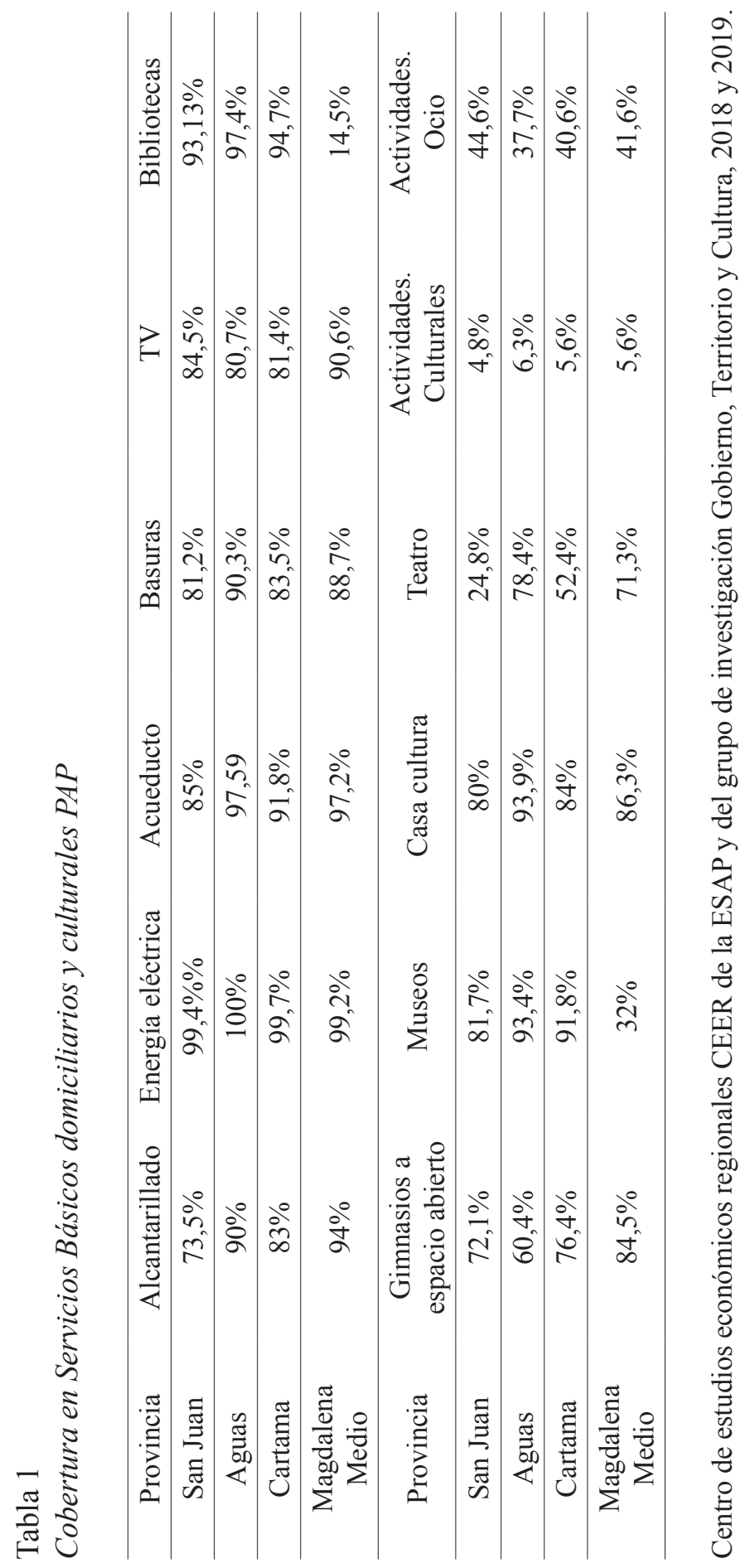




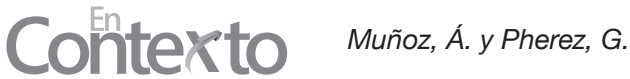

A manera general los municipios que integran las Provincias poseen una muy buena cobertura en servicios básicos domiciliarios como saneamiento básico o recolección de basuras, el cual está por encima del $80 \%$. Dato que es relevante, si se toma en cuenta que son municipios agrícolas con baja densidad poblacional. La Provincia de San Juan es la que menor cobertura tiene en alcantarillado y en recolección de basuras, es decir, son los municipios con menor cobertura en servicios de saneamiento básico (Tabla 1).

En espacios culturales, los municipios que integran las Provincias cuentan con casas de la cultura en más de un $80 \%$. Las Provincias de San Juan, Aguas y Cartama cuentan con museos en más de un $81 \%$, lo que fortalece la cultura. En la Provincia de San Juan solo el 24,8\% de los municipios cuenta con teatros culturales; y en la Provincia de Cartama, la mitad de los municipios posee teatros culturales. En el Magdalena Medio, el 84,5\% de los municipios ofrece gimnasios a espacio abierto y el $32 \%$ cuenta con museos culturales. Sin embargo, menos del 10\% de los jóvenes adolescentes de un décimo grado participa en actividades culturales o del ocio creativo.

Más del 40\% de los jóvenes de las Provincias de San Juan, Cartama y Magdalena Medio dedica su tiempo libre a actividades de ocio no creativo. En otras palabras, el $70 \%$ o más de los jóvenes dedica su tiempo libre a actividades de deporte y ocio no creativo; el resto del tiempo, lo dedican principalmente a estudiar o hacer tareas escolares. La investigación encontró que menos del 4\% de los estudiantes afirma poseer empleo o trabajar.

\section{Provincia de San Juan}

\section{Satisfacción con el gobierno y el progreso económico de la municipalidad}

Para el logro de una ciudad feliz, la administración pública se convierte en la acción que dinamiza la inversión de los recursos públicos en bienes socialmente necesarios que contribuyen al bienestar de la sociedad, es decir, del uso eficiente y efectivo de los impuestos que todos los ciudadanos pagan y se recaudan. Una buena administración pública, en términos aristotélicos, consiste en hacer de la política el bien supremo, y "ésta pone el máximo empeño en hacer a los ciudadanos de una cierta cualidad y buenos e inclinados a hacer el bien" (Aristóteles, 2018, 1099b). Es decir, a ser solidarios, a procurar el bien para sí y los demás; para ello, todo ser humano busca hacer realidad sus sueños, crecer en su humanidad social junto con los otros; de allí "que sea razonable no llamar feliz a un buey, un caballo o ningún otro animal, pues ninguno de ellos es capaz de participar en una actividad semejante" (Aristóteles, 2018, 1100b). 
Afirman Gehl (2010), Acemoglu y Robinson (2012) que la mala administración del gobierno es la fuente de todos los males sociales, que allana de pobreza moral, económica y social a todos sus ciudadanos hasta acabar con su calidad de seres libres. Para demostrar la anterior afirmación, comencemos por preguntarnos: ¿cómo califican los jóvenes-adolescentes de undécimo grado de la Provincia de San Juan sus gobiernos? ¿Cómo ven el futuro de sus regiones para la realización de sus proyectos de vida? (Tabla 2). 
Contex to Muñoz, A. A Pherez, $G$.

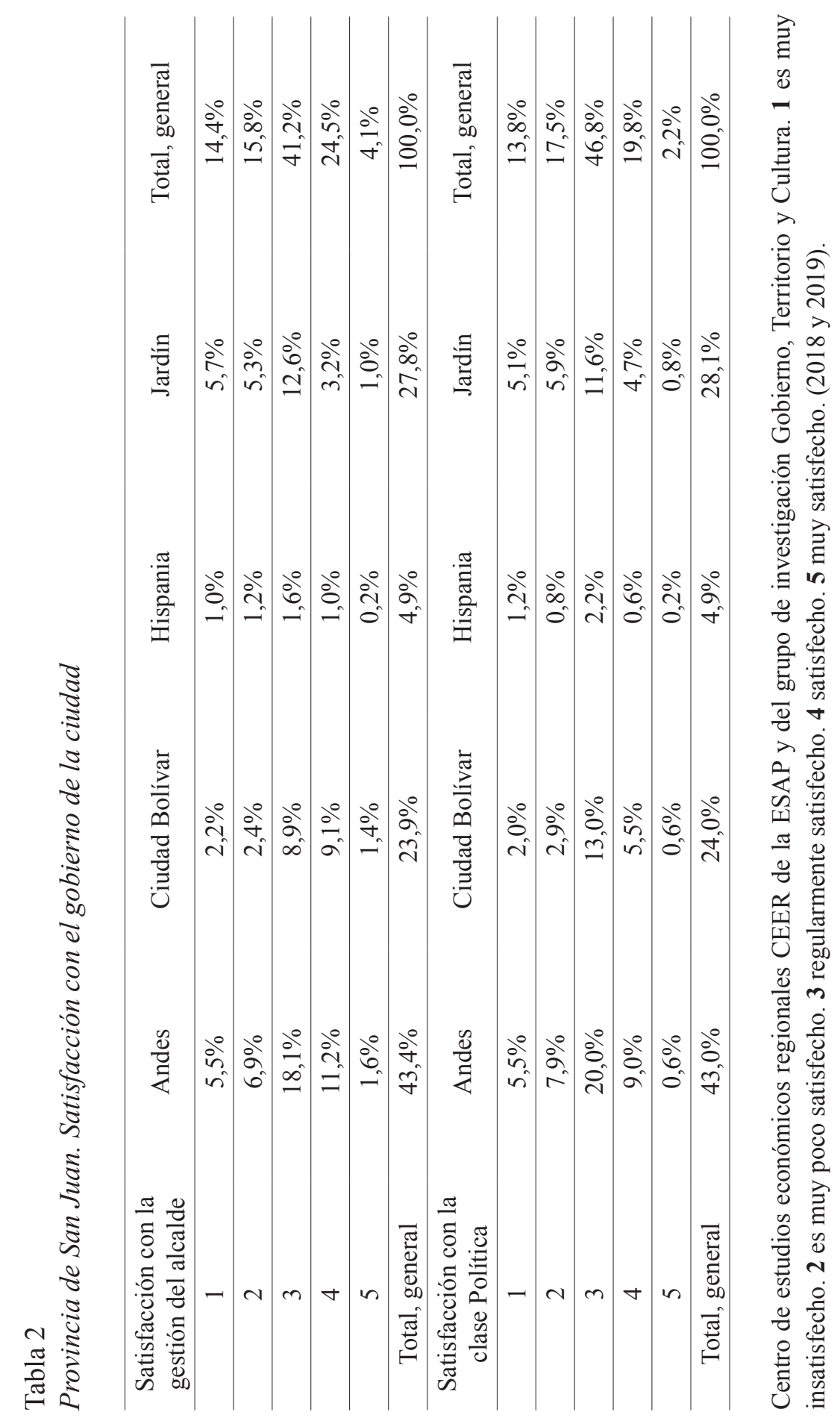


Si bien, el 28,6\% de los jóvenes-adolescentes de undécimo grado de la Provincia de San Juan afirma estar muy satisfecho con la administración de sus gobiernos locales, el 30,2\% afirma estar insatisfecho con las administraciones locales de sus municipios; y para el $41,2 \%$ de los adolescentes de undécimo grado de la Provincia de San Juan la administración local es regular. Es decir, existe una tendencia de insatisfacción, en otras palabras, para el 71,4\% de los adolescentes de undécimo grado la administración pública es regular con tendencia a mala.

Niveles de satisfacción con la administración pública municipal que van en línea con los de la clase política local, es decir, con un nivel de correlación $\mathrm{r}^{2}$ entre las variables del $90 \%$. Para el $46,8 \%$ de los adolescentes, la clase política de sus localidades es muy regular, no son confiables sus promesas. De allí que el 31,3\% de los estudiantes califique la clase política de su localidad como mala (niveles de satisfacción entre 1 y 2 ) y el 28,6\% de buena o satisfactoria (niveles de satisfacción entre 3 y 4). En otras palabras, tanto el gobierno local como la clase política de la Provincia de San Juan son evaluadas principalmente de regulares, $\mathrm{r}^{2}=0,9$.

Preguntémonos ahora: ¿cuál es el nivel de satisfacción de los jóvenes adolescentes con su ciudad en términos de seguridad y de progreso económico? Dos variables que son fundamentales en la valoración de los proyectos de vida, es decir, de la realización de sus expectativas futuras de autorrealización en el municipio. Se espera que a menores expectativas de autorrealización mayores son los ánimos migratorios en la población adolescente. 
Contex to Muñoz, A. A. Pherez, $G$.

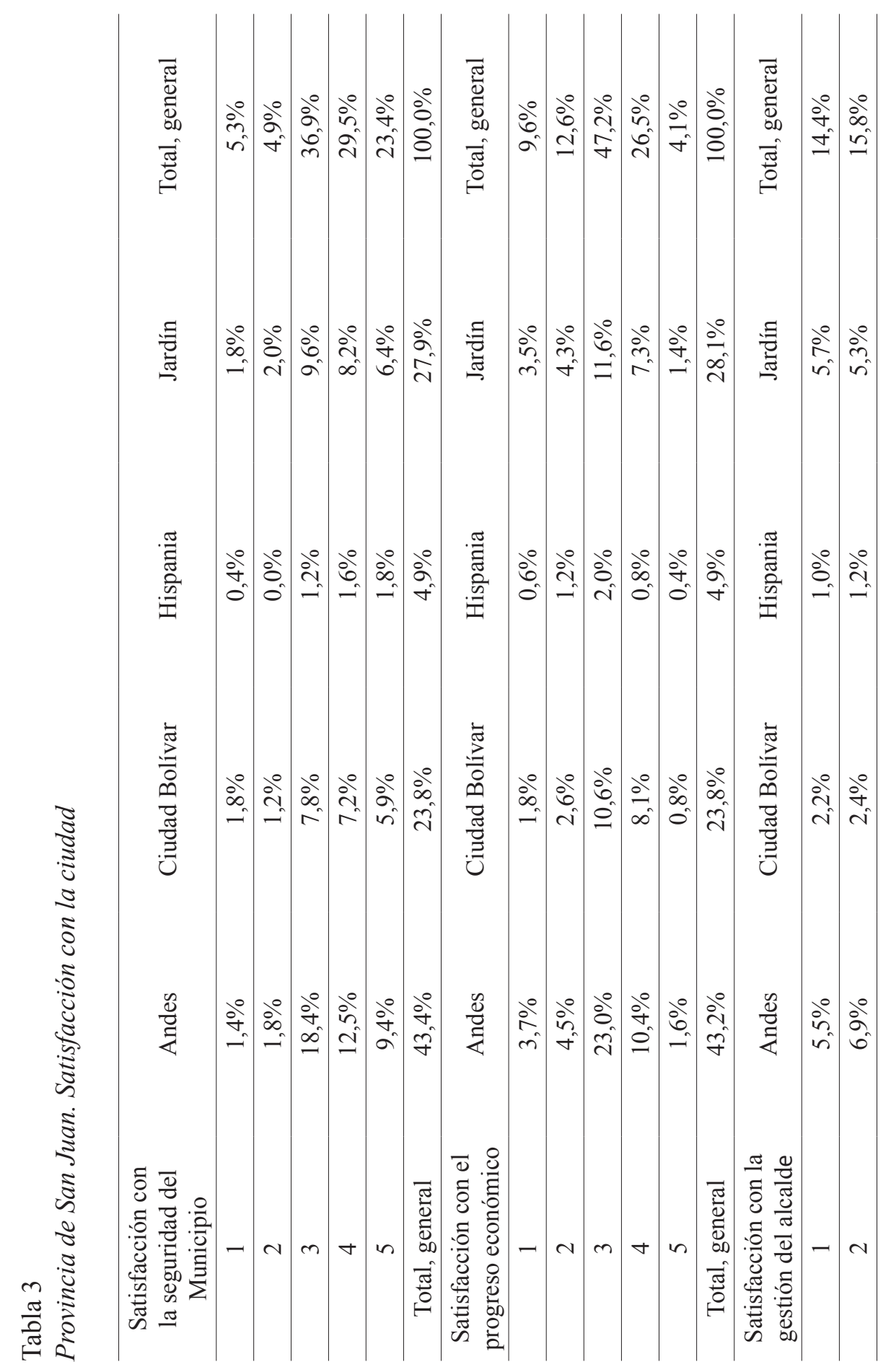




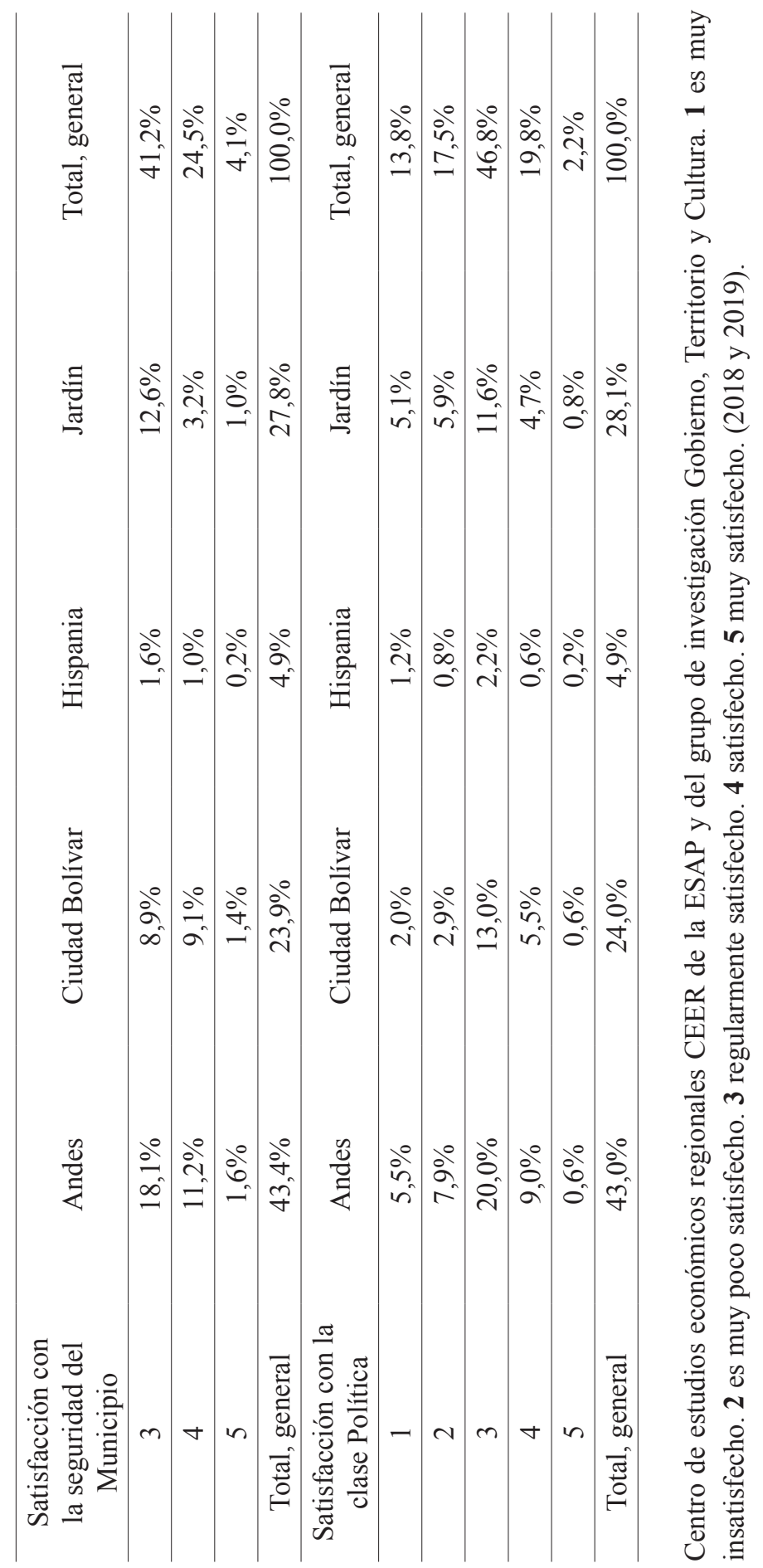




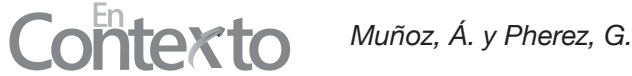

Según la Tabla 3, más del $71 \%$ de los jóvenes-adolescentes percibe que en su municipio hay progreso económico futuro, incluso están muy satisfechos con la seguridad local. Indicador que se complementa con los datos de la Tabla 1, en la que los adolescentes de undécimo grado disfrutan de una muy buena infraestructura municipal en servicios públicos básicos domiciliarios, por encima del $80 \%$ en cobertura; de la existencia de buenos recursos naturales, por encima del $94 \%$ y de un buen cubrimiento cultural en bibliotecas y gimnasios a espacio abierto.

Sin embargo, con una correlación del $80 \%$ entre las variables satisfacción con el gobierno local y la clase política, $\mathrm{r}^{2}=0,8$, los jóvenes adolescentes manifiestan estar muy regularmente satisfechos (Tabla 3), la razón principal, según la entrevista focal con los estudiantes en los municipios de Andes y Ciudad Bolívar, es la amenaza de venta de los recursos naturales a multinacionales mineras y la pérdida de la confianza en la clase política.

Ahora la pregunta es por el proyecto de vida y su permanencia en el municipio. De acuerdo con las transferencias nacionales fiscales del sistema general de participación, el gobierno nacional exige a los municipios invertir el 58,5\% de los recursos fiscales percibidos en educación. En el marco de una eficiencia administrativa, en el gasto público, se espera que los municipios retengan al menos el 58,5\% de los jóvenes que forma. 


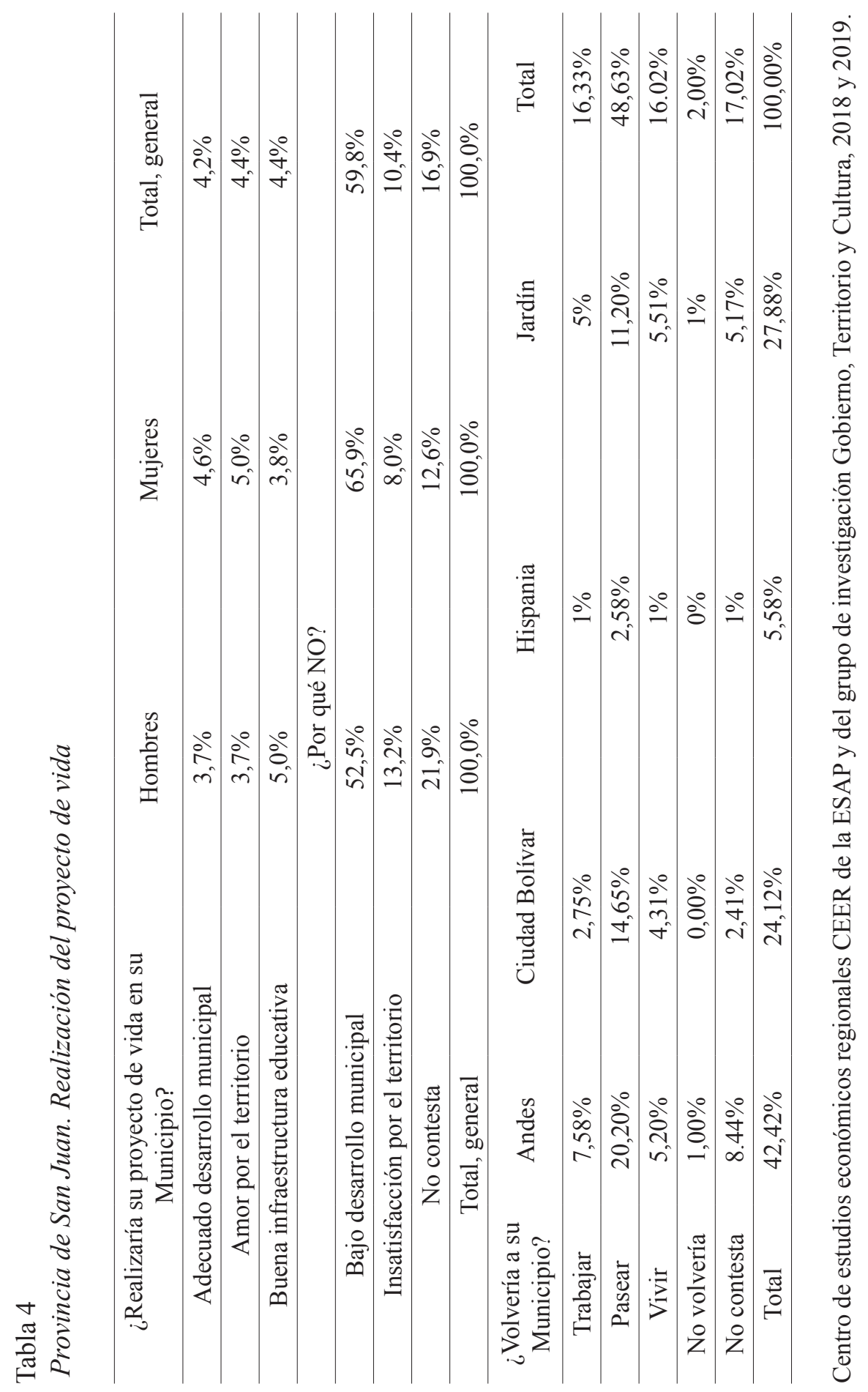




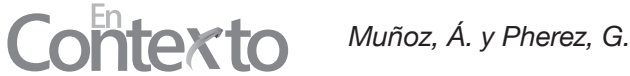

De acuerdo con la Tabla 4, en la Provincia de San Juan, el 100\% de los estudiantes que se forma como bachilleres, solo puede llegar a fidelizar el $32,35 \%$, es decir, el $67,65 \%$ de los adolescentes que se forman como bachilleres en dichos municipios tiende a emigrar de manera definitiva. Ellos sueñan con estudiar y llevar una vida profesional por fuera de su municipio natal. La mayoría de los estudiantes talentosos de undécimo grado que se forman en la Provincia de San Juan emigrarían para buscar mejor futuro. El 48,63\% regresaría solo a pasear, pero no a vivir o trabajar. Para el 59,8\% de los estudiantes de undécimo grado, sus municipios poseen bajo desarrollo económico; no hay posibilidades laborales que sean buenas para un profesional. La mayoría de los adolescentes talentosos que terminan el bachillerato y se quedan en el municipio es para trabajar en actividades que no demandan buena formación profesional.

En conformidad con otros estudios de felicidad urbana (Muñoz, 2018; 2019a; 2019b) y de emprendimiento y felicidad (Muñoz y Martínez, 2020), se observó que los municipios de la Provincia de San Juan ofrecen buenos servicios básicos domiciliarios a sus moradores (Tabla 1). Los ciudadanos cubren en buena medida sus necesidades básicas domiciliarias y de espacios de recreación, incluso el estudio halló que dichos municipios poseen buena infraestructura de ciudad, gozan de buena seguridad y buena percepción de progreso económico. Entonces, ¿por qué la amenaza de migración de jóvenes bachilleres es de más del 67\%? ¿Por qué la amenaza de pérdida de inversión en educación por más de 11 años supera el $67 \%$ ?

Si bien, los jóvenes adolescentes manifestaron estar satisfechos con el progreso económico y la seguridad interna del municipio con una correlación del $82 \%$, es decir, $\mathrm{r}^{2}=0,82$, ellos no ven su futuro económico de autorrealización en sus municipios, no perciben la existencia futura de desarrollo local.

En conclusión, la administración del gobierno de la Provincia de San Juan debe trabajar por el desarrollo económico de sus municipios a partir de la innovación empresarial. Estimular el emprendimiento y creación de nuevas empresas; aprovechar más el tiempo libre de ocio que tienen los jóvenes, a través del fomento cultural con fines creativos. La clase política y los gobiernos locales deben trabajar por la conservación de los recursos naturales, tal y como lo promulga la asociación municipal de las Provincias. Estimular la autorrealización de sus adolescentes, de tal manera que se mejoren las expectativas de permanencia de sus jóvenes talento en el territorio. 


\section{Provincia del Aguas, Bosques y Turismo}

\section{Satisfacción con el gobierno y el progreso de económico de la municipalidad}

Para el 54,2\% de los jóvenes-adolescentes de undécimo grado de la Provincia de Aguas, Bosques y Turismo sus gobiernos locales son regulares; para el 29,9\% son malos y para el $14 \%$ son buenos. Es decir, los estudiantes los evalúan de regulares con tendencia a ser malos gobiernos. De igual manera, con una correlación explicativa de las variables de satisfacción con el gobierno local y de la clase política municipal del $83 \%, \mathrm{r}^{2}=0,83$, los jóvenes adolescentes de siete municipios evaluaron la clase política de sus localidades de regulares con tendencia a mala (Tabla 5). Los municipios de Granada, San Luís y Guatapé fueron en donde más del $20 \%$ de los adolescentes de undécimo grado cree en la clase política de sus municipios. 
Contexto Muñoz, A. A. Pherez, G.

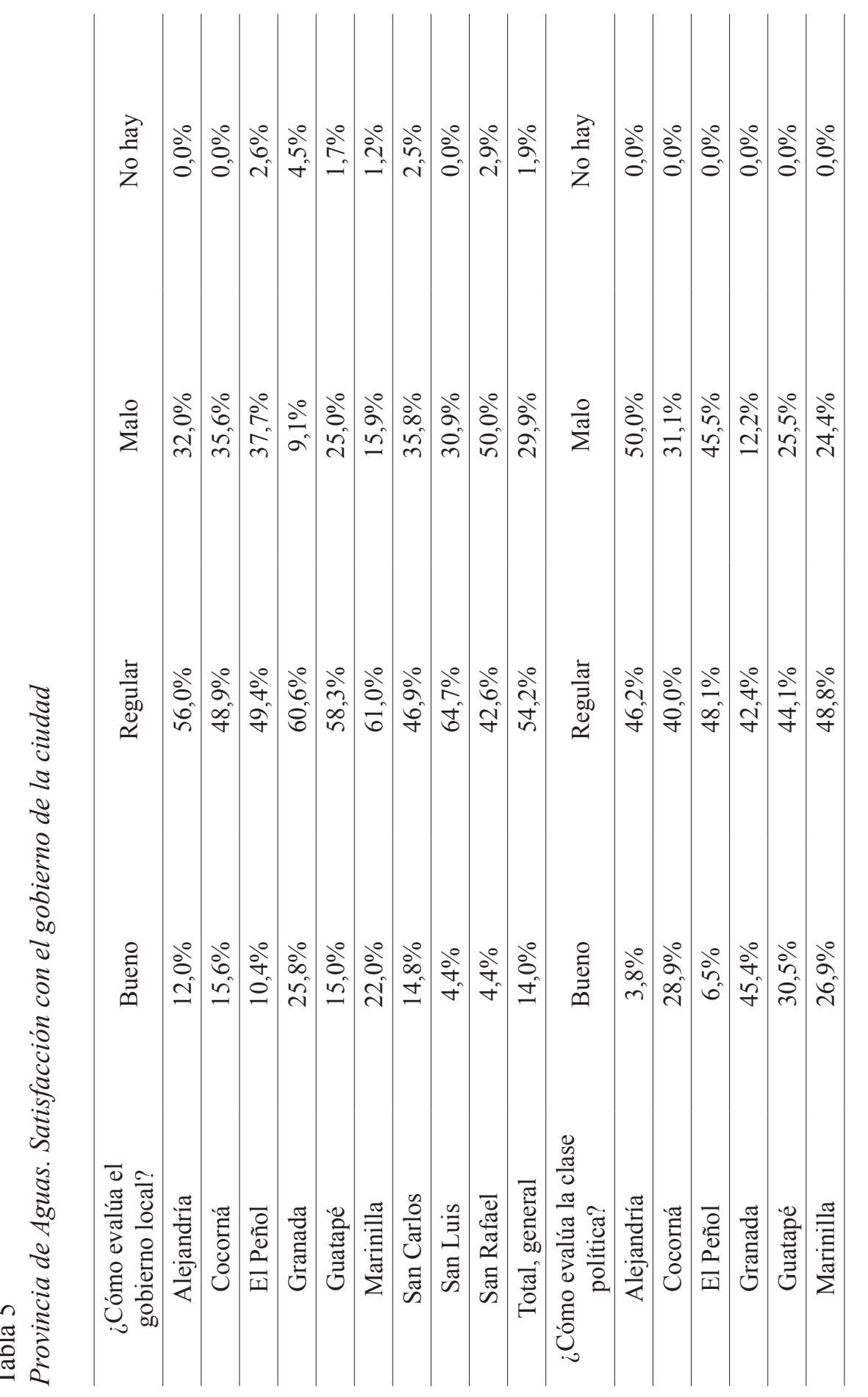




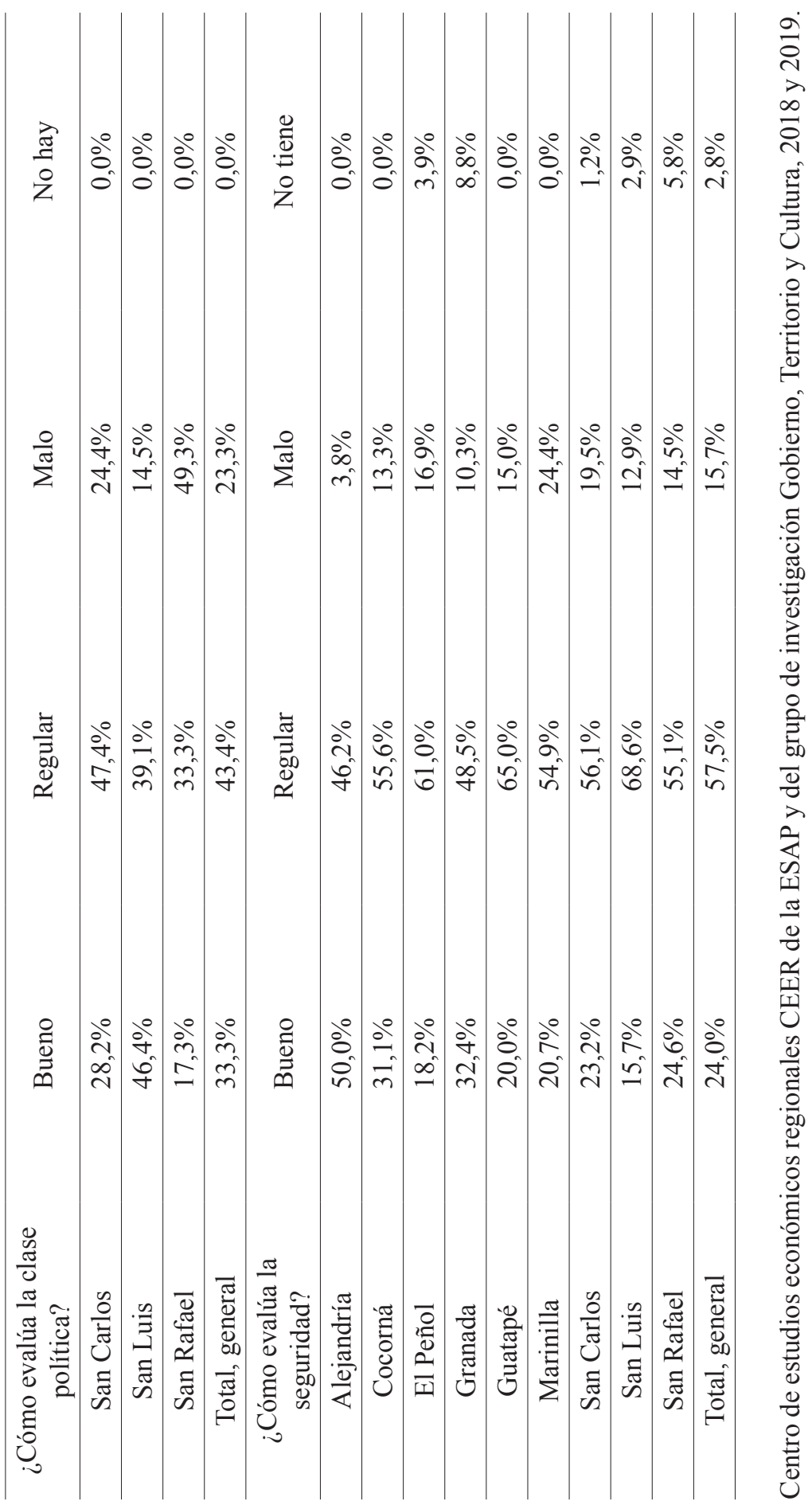




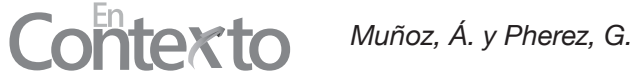

Llama la atención los municipios de Alejandría y El Peñol, en donde el porcentaje de evaluación a la clase política y al gobierno local es principalmente malo, menos del $12 \%$ de los adolescentes califican la gestión del alcalde de buena, la credibilidad en la clase política es muy regular, con tendencia a mala. En dos entrevistas focales realizadas en los municipios de Alejandría y El Peñol, los estudiantes manifestaron su desencanto principalmente por el bajo mantenimiento de la red vial y los altos niveles de corrupción; municipios donde los gobernantes pertenecen a una misma familia, lo que no ha favorecido el crecimiento económico (Tabla 5).

Los municipios de Marinilla, Cocorná, Granada, San Carlos y Guatapé son las mejores evaluadas por los jóvenes-adolescentes. Sin embargo, son los municipios en donde los estudiantes de undécimo grado manifestaron poseer gobiernos muy regulares, al punto de calificarlos de inexistentes. Esos mismos municipios afirman tener una clase política mala, muy especialmente en Alejandría, El Peñol, Guatapé, Marinilla, San Carlos y San Rafael.

La pregunta que sigue es: ¿cómo perciben los jóvenes adolescentes de undécimo grado el futuro económico y laboral de sus municipios? Con una correlación del 90\%, entre las variables: satisfacción con el gobierno, la clase política y el desarrollo económico, $\mathrm{r}^{2}=0,9$, los adolescentes de undécimo grado califican el futuro económico y laboral como regular. Principalmente, los estudiantes de Alejandría, Cocorná, San Luís, San Rafael y El Peñol. Los estudiantes de los municipios de Granada, Guatapé y Marinilla creen ver mayor futuro económico y laboral. 


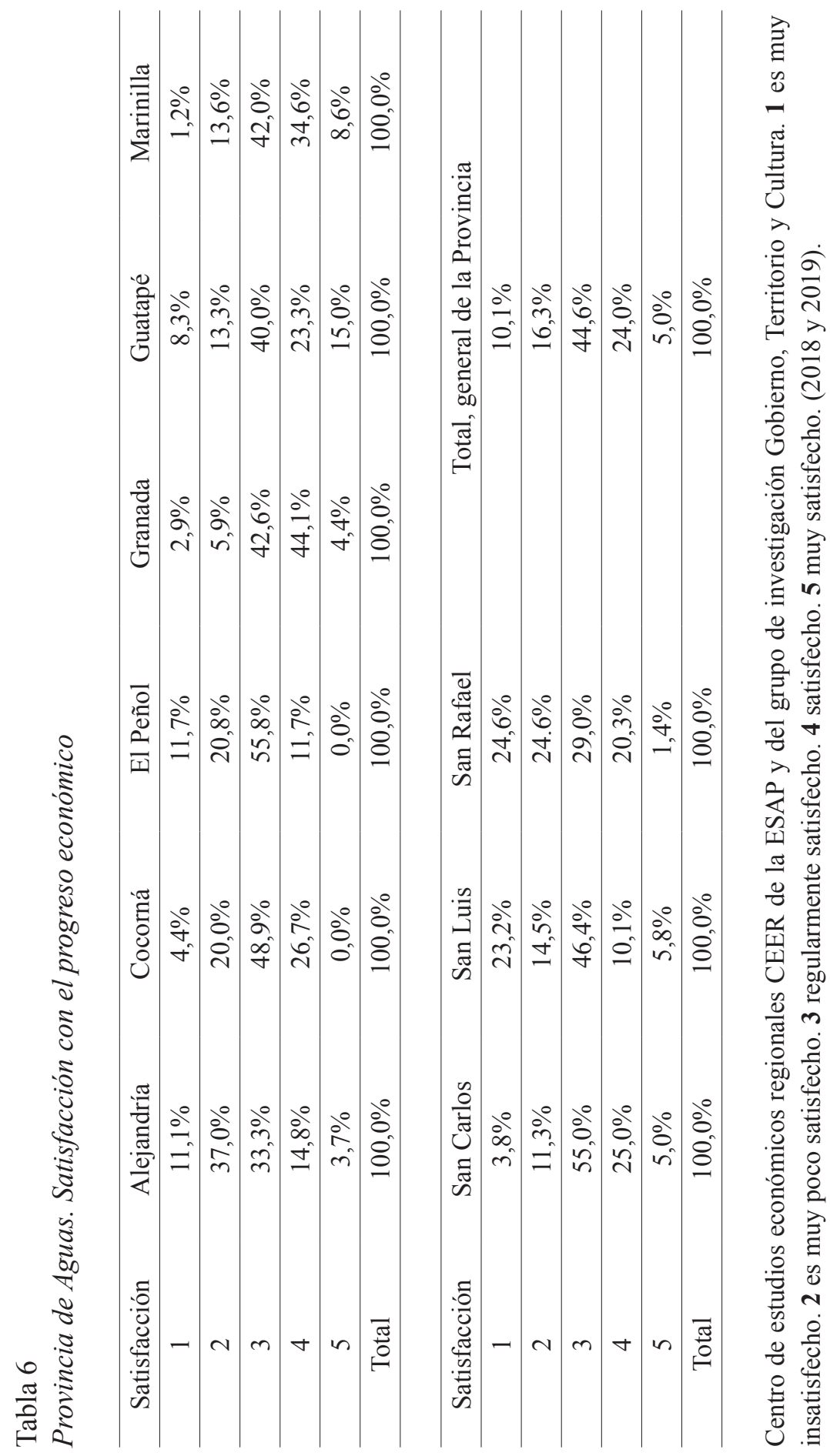




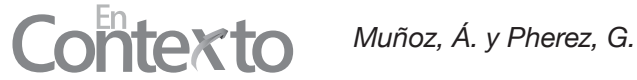

Según la Tabla 5, en siete de los nueve municipios de la Provincia de Aguas, Bosques y Turismo la seguridad es regular con tendencia a buena, ya que para el 57,5\% de los estudiantes las acciones de seguridad que brinda la policía en sus localidades son regulares, y para el $24 \%$ son buenas. Solo el $15,7 \%$ de los jóvenes-adolescentes afirmó que eran malas y el 2,8\% las evalúo de inexistentes.

Obsérvese que entre los datos municipales de las Tablas 5 y 6 existe una correlación realmente alta, $\mathrm{r}^{2}=0,8$. Los municipios mal evaluados en su gestión administrativa pública son a su vez los municipios donde los jóvenesadolescentes no ven futuro económico, no creen que puedan realizar sus sueños o sus proyectos de vida, como lo muestra la Tabla 7. 


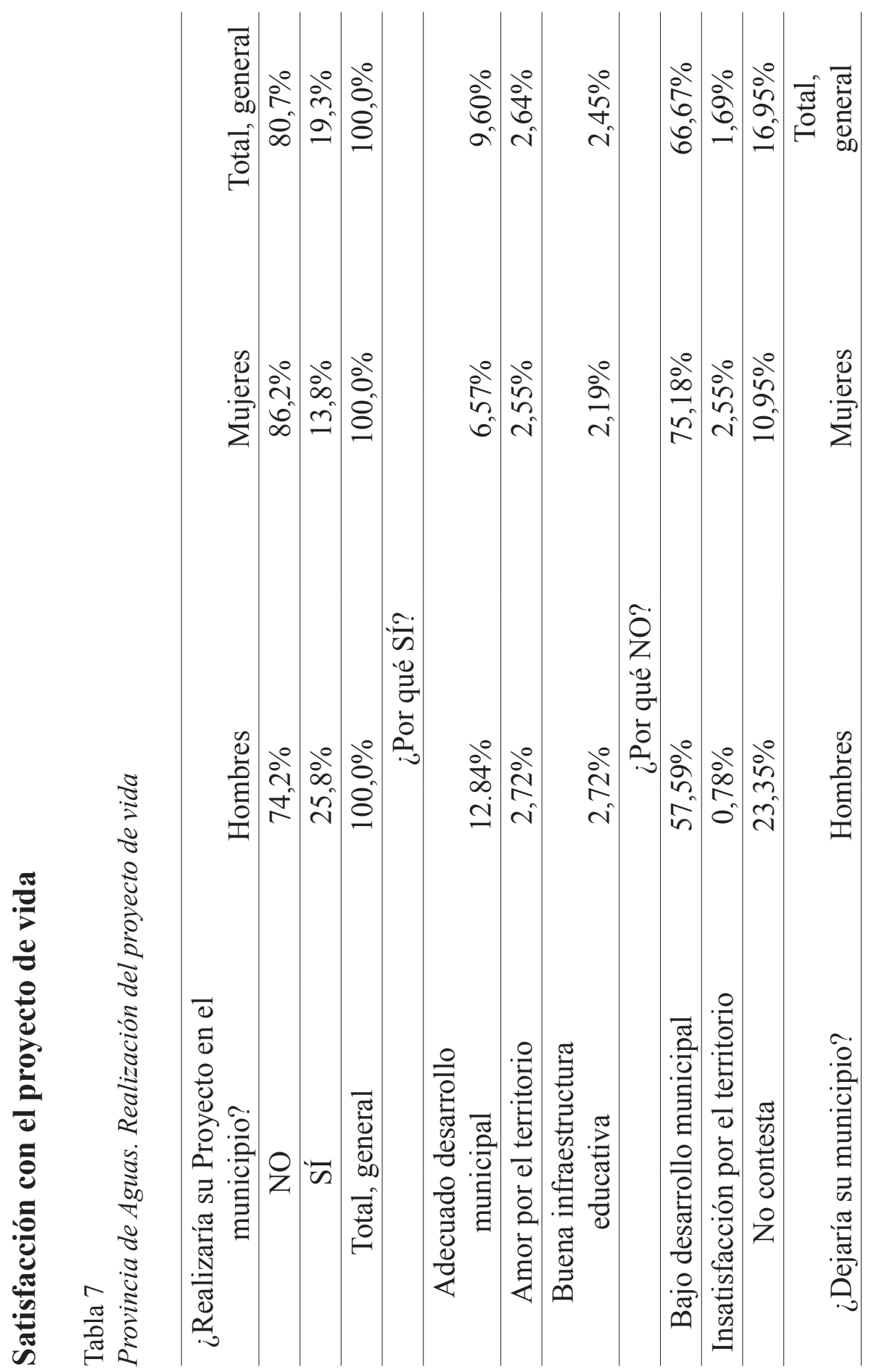


Contexto Muñoz, A. A. Pherez, $G$.

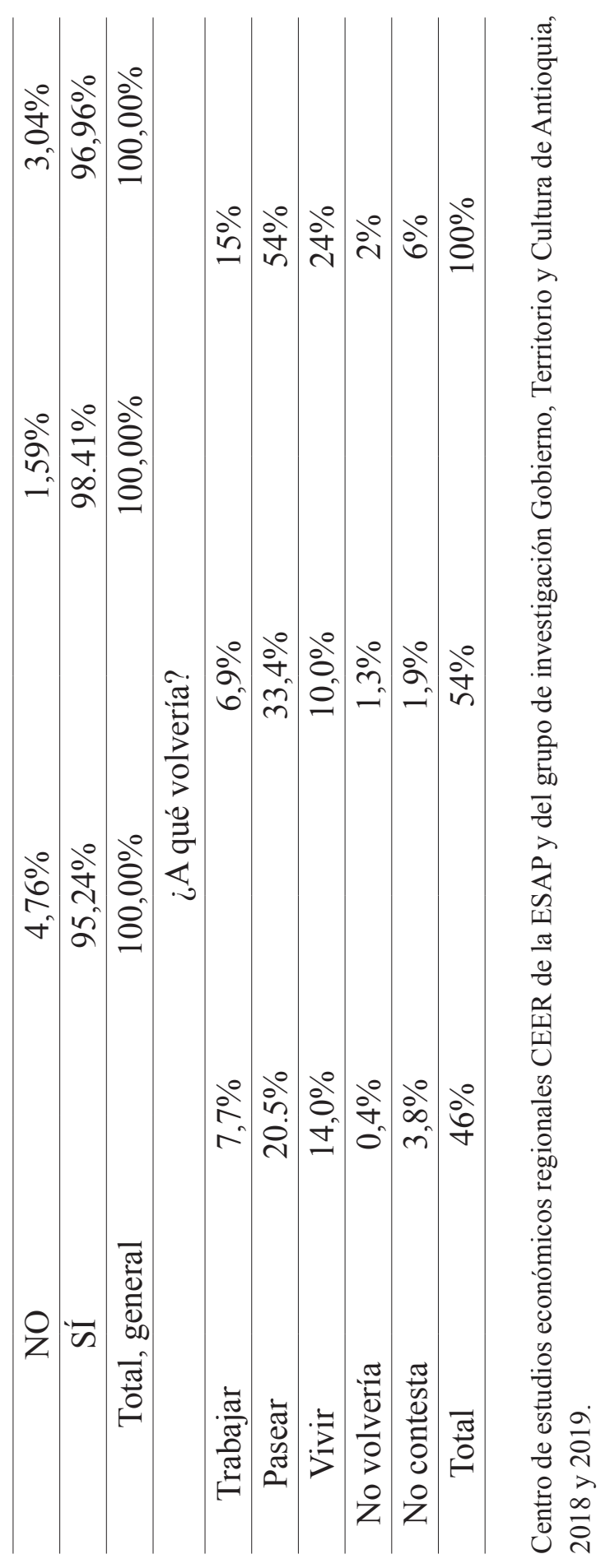


San Rafael y San Luís son los municipios más mal evaluados en lo administrativo y en su desarrollo económico; son igualmente, los más regulares y mal evaluados en la satisfacción con la seguridad que brinda la policía. Por el contrario, los municipios de Marinilla, Guatapé y Cocorná tuvieron los gobiernos mejor evaluados de la Provincia y son, a su vez, los de mayor expectativa de crecimiento económico en los jóvenes-adolescentes de undécimo grado.

Según la entrevista focal, realizada en los municipios de El Peñol y Alejandría, el 69,6\% de los estudiantes cree que la Provincia de Aguas, Bosques y Turismo tiene mejor futuro económico con la integración de sus municipios; sin embargo, el $80,7 \%$ no realizaría su proyecto de vida en el municipio y el $96,96 \%$ afirma dejar su municipalidad para realizar su proyecto de vida (Tabla 7). Datos estadísticos que obligan a las administraciones públicas locales a repensar los indicadores de retención de jóvenes talento para mejorar el desarrollo económico-social, de lo contrario corren el riesgo de perder lo más valioso de su inversión social, los jóvenes.

El 66,67\% de los jóvenes-adolescentes de undécimo grado afirma no realizar su proyecto de vida en el municipio en el cual viven por el bajo desarrollo; de allí que el $96,96 \%$ prefiera irse a otros municipios, de ellos, solo el 39\% desearía regresar a trabajar y vivir. La Provincia de Aguas, Bosques y Turismo corre el riesgo de perder el $61 \%$ de los bachilleres que formó y financió con sus ingresos públicos; dato que es muy relevante si se toma en cuenta que dicha Provincia goza de la existencia de buenas universidades.

De acuerdo con la Tabla 1, el 6,3\% de los adolescentes dedica su tiempo libre al ocio creativo: estudiar una segunda lengua, tocar piano o guitarra, pintar al óleo o escribir poesía, y el $37,7 \%$ dedica su tiempo al ocio no creativo: tomar licor, ver televisión, sentarse en el parque o charlar con amigos. Dada la existencia de buena infraestructura municipal, la administración pública debería fortalecer la inversión realizada en educación con el fomento de actividades culturales, tales como el estímulo al emprendimiento creativo e innovador. Lo que ayudaría al crecimiento y desarrollo local, tanto en infraestructura productiva como social. Se concluye que, en los municipios de la Provincia de Aguas, Bosques y Turismo, es necesario mejorar en los jóvenes la confianza en el servicio de seguridad policial, ya que el $57,5 \%$ de los estudiantes de undécimo grado la califica de regular, el 18,5\% afirman que es malo o no existe; solo el $24 \%$ afirma que es bueno, es decir, confía en ella. Según las entrevistas focales, realizadas en los municipios de Alejandría y El Peñol, el 54,1\% de los adolescentes no está satisfecho con las relaciones de sus vecinos, por la falta de control en los 


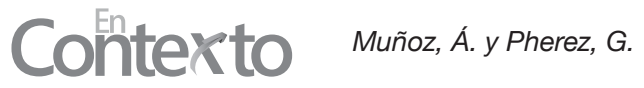

niveles de ruido con equipos de sonido. No es que la Provincia sea insegura, pues más del $72 \%$ considera que sus municipios son seguros, según la Tabla 5 , sino que la falta de control público facilita el desorden social y perdidas en la calidad de vida.

\section{Provincia de Cartama}

Satisfacción con el gobierno y el progreso de económico de la municipalidad

Del total general de los 11 municipios de la Provincia de Cartama con una confianza estadística del 95\% y un margen de error del 5\%, la investigación halló que el 76,1\% de los estudiantes de undécimo grado está muy regularmente satisfechos con la gestión de sus alcaldes, (Tabla 8). Siendo los más inconformes los jóvenes-adolescentes de undécimo grado de Caramanta y Santa Barbara. Los adolescentes de undécimo grado de Montebello, La Pintada, Valparaíso y Támesis están muy regularmente satisfechos. 


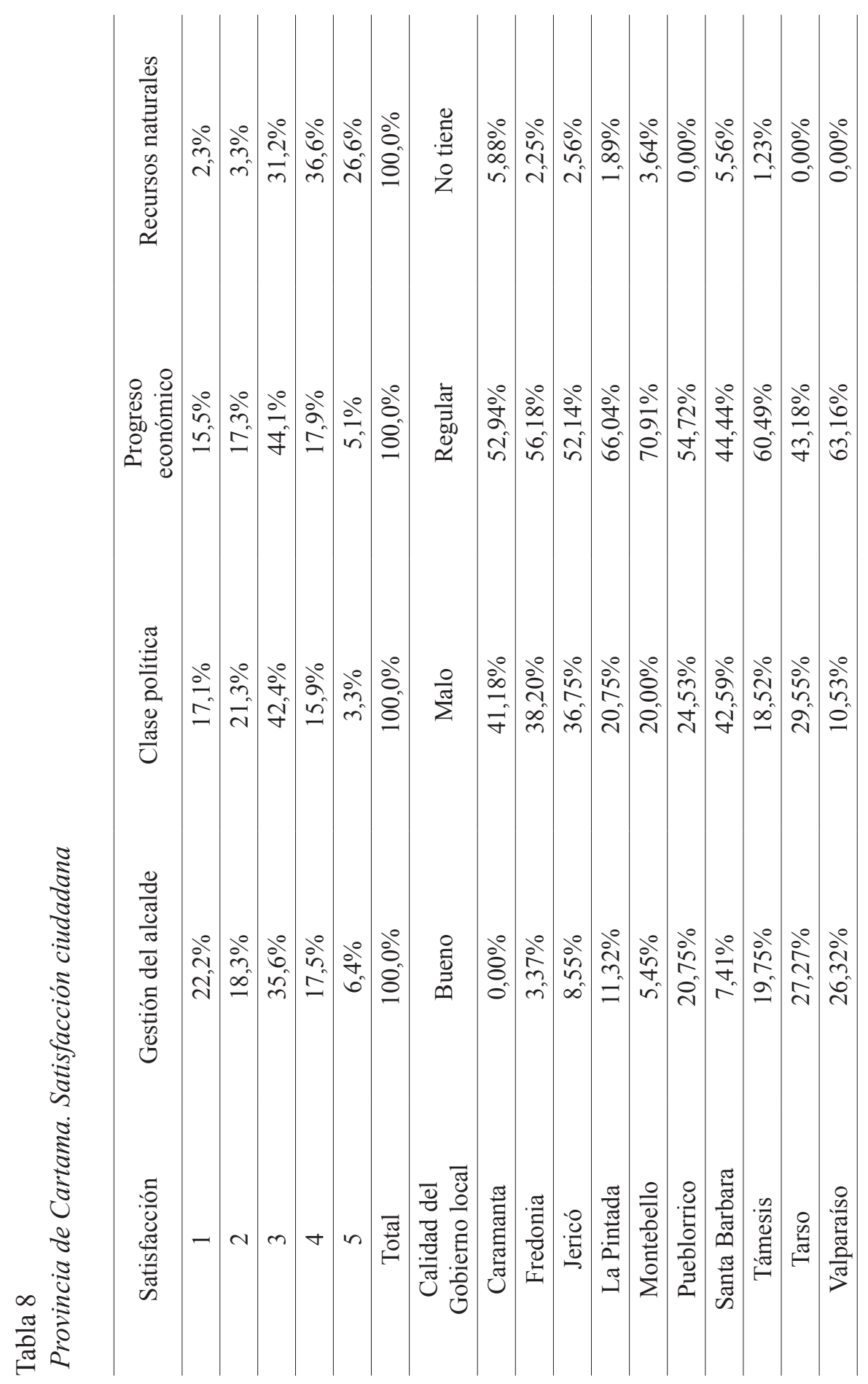




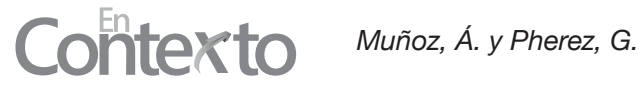

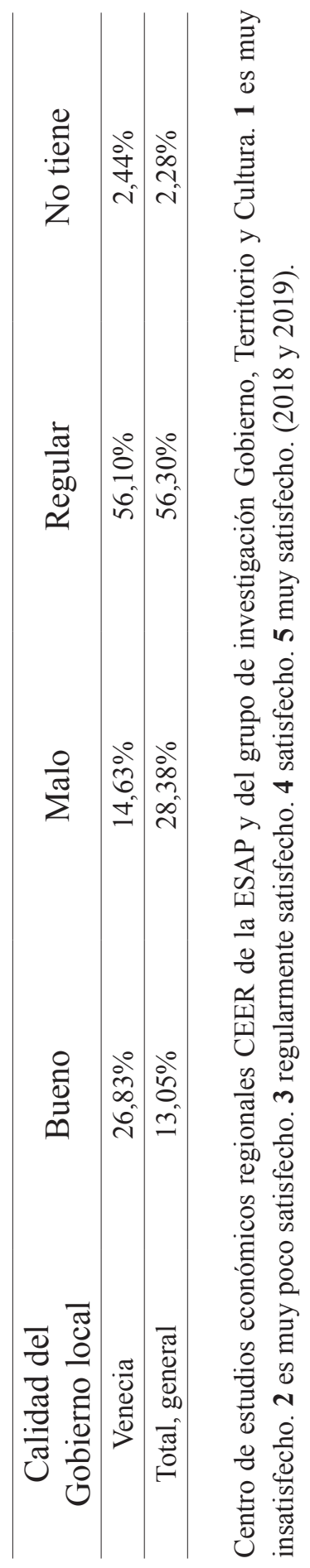


Entre el 20\% y el 26,8\% de los adolescentes de undécimo grado de Pueblorrico, Tarso, Valparaíso y Venecia evalúa la calidad de sus gobiernos locales como bueno. Sin embargo, al menos 9 de los 11 municipios de la Provincia son evaluados como regulares en su administración local.

Dichas insatisfacciones muestran una correlación del 92\% entre las variables: satisfacción con el gobierno local, la clase política y con el crecimiento económico, $\mathrm{r}^{2}=0,92$. Si el gobernante es muy regular, la clase política es también muy regular y, por tanto, no hay crecimiento económico. En dos entrevistas focales realizadas en los municipios de Santa Barbara y Caramanta, la insatisfacción generalizada giró alrededor de la corrupción política, la delincuencia común y la explotación minera. En el municipio de Caramanta, el $14,7 \%$ de los adolescentes manifestó estar muy insatisfechos con sus vecinos; el 18,2\% de los estudiantes de Santa Barbara y el 13,1 de Fredonia están muy insatisfechos con la seguridad de sus municipios. 
Contexto Muñoz, A. A. Pherez, $G$.

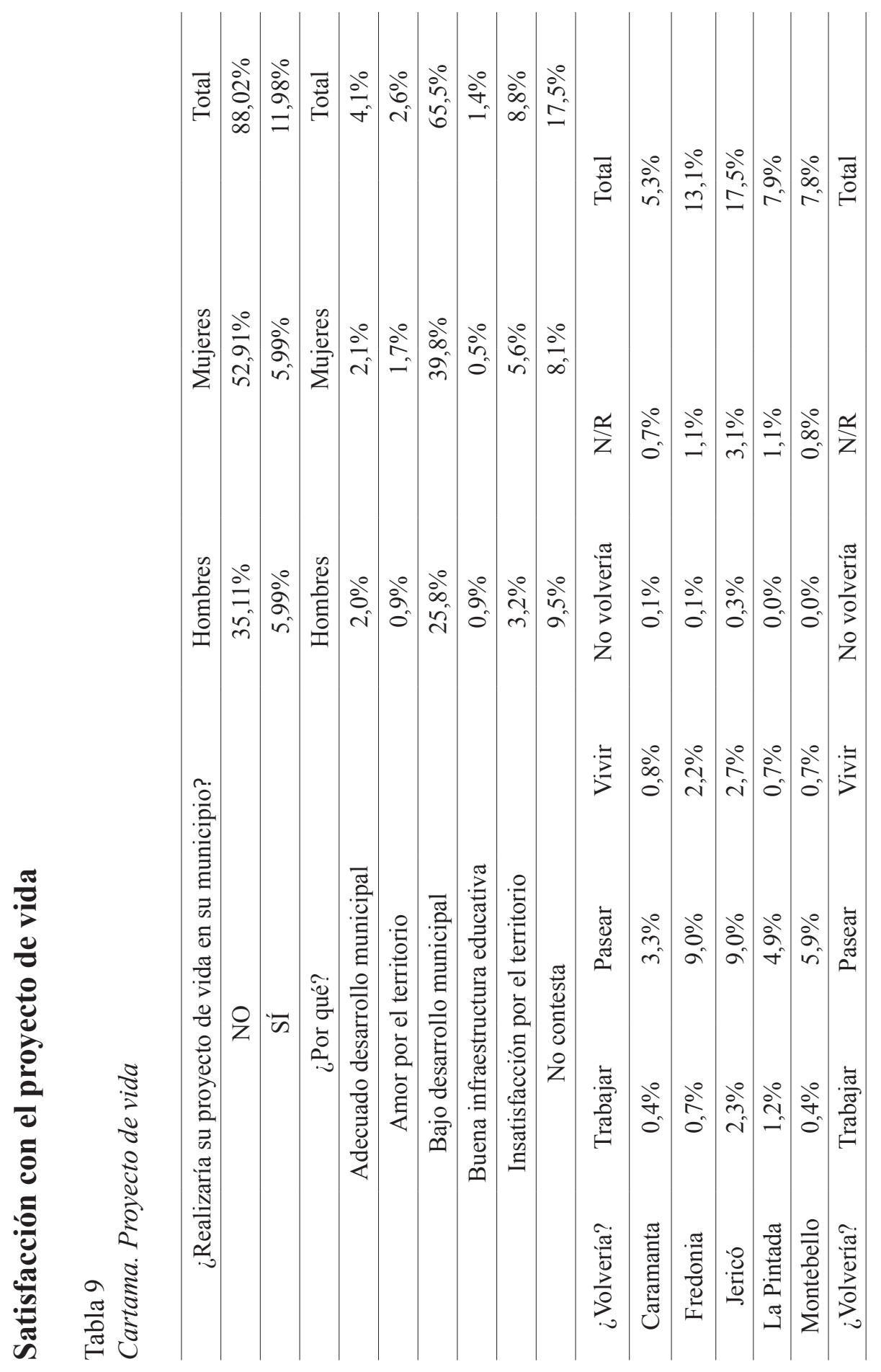




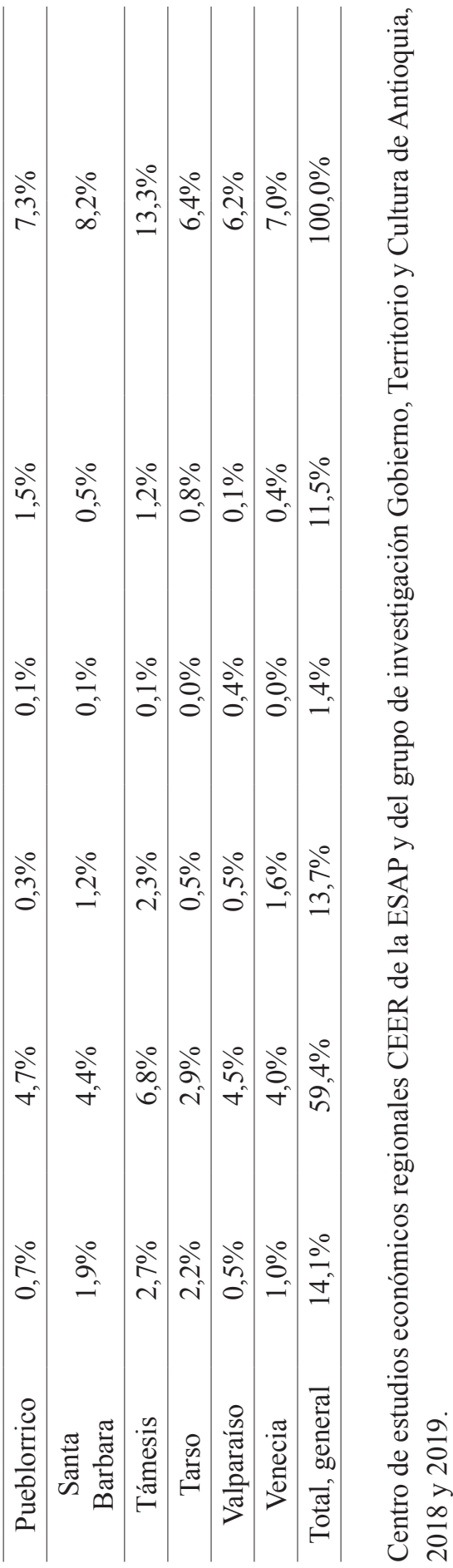




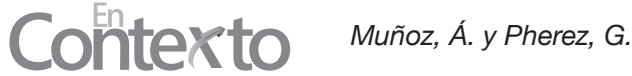

Los factores de inseguridad y los malos gobiernos hacen que las expectativas de crecimiento económico sean bajas. Si bien, el $84,4 \%$ de los jóvenes-adolescentes de undécimo grado evalúa los recursos naturales como muy satisfactorios, ellos temen por su desaparición, si se les permite a las multinacionales mineras explotar el subsuelo (Tabla 8).

El bajo crecimiento económico de la provincia de Cartama, sumado a la amenaza de explotación minera en Jericó y a la inseguridad por delincuencia común, lleva a los adolescentes bachilleres a permanecer incrédulos respecto a la realización de sus proyectos de vida en sus municipios. De allí que el $88,02 \%$ de los adolescentes talentos de undécimo grado no desee realizar en sus municipios su proyecto de vida (Tabla 9).

Para el 65,5\% de los adolescentes de undécimo grado, el bajo desarrollo local y las expectativas de no crecimiento, los obliga a emigrar. No les permite quedarse para realizar allí sus proyectos de vida. De ellos, el 27,8\% se quedaría viviendo y trabajando en sus localidades, es decir, $72,2 \%$ de los talentos abandonarían definitivamente la municipalidad; incluso el $59,4 \%$ de los bachilleres desea regresar solo a pasear, no a vivir ni a trabajar. Estos son bachilleres de Jericó, Fredonia y Montebello (Tabla 9).

Se concluye: si bien los municipios de la Provincia de Cartama gozan de buenos espacios públicos culturales y de buena infraestructura en servicios básicos domiciliarios (Tabla 1), el 72,2\% de los jóvenes adolescentes de undécimo grado prefiere migrar a otros municipios para lograr su autorrealización laboral, a pesar de tener buenos vecinos, afirmó el 69\% de los adolescentes talento respectivamente.

Los anteriores resultados obligan a las nuevas administraciones públicas locales a gestionar e invertir más en el tiempo libre de los adolescentes. E1 $40,6 \%$ de los adolescentes manifiesta dedicar su tiempo libre al ocio no creativo y el 5,6\% aprovecha su tiempo libre en actividades culturales (Tabla 1). Si la administración pública local invierte más de los recursos públicos en el aprovechamiento del tiempo libre de los adolescentes talento, mejora las relaciones interpersonales entre vecinos e incluso el crecimiento económico a través del emprendimiento creativo e innovador, se mejoran las éticas de solidaridad y cohesión social como lo plantean Camps y Giner (2014). 


\section{El Magdalena Medio}

\section{Satisfacción con el gobierno y el progreso económico de la municipalidad}

Los jóvenes-adolescentes del Magdalena Medio manifiestan tener una alta insatisfacción con los gobiernos locales. Para el 71,2\% de los jóvenes adolescentes de undécimo grado la gestión de los alcaldes ha sido muy regular o muy insatisfactoria; de igual manera, ellos evalúan la gestión de la clase política en sus localidades; el 72,3\% dice que es muy regular e insatisfactoria. Con una correlación estadística entre las variables: gobierno local y clase política del $\mathrm{r}^{2}=0,96$, los jóvenes adolescentes del Magdalena Medio manifiestan estar altamente insatisfechos con el alcalde de su municipio y la clase política. En Puerto Nare, por ejemplo, el 68\% de los adolescentes afirma estar insatisfechos y muy insatisfechos con la gestión del alcalde, solo el $8 \%$ de los adolescentes manifestó estar satisfechos y muy satisfechos. Y cuando a los mismos estudiantes se les pregunta a cerca de la satisfacción con la clase política de su municipio, el 62\% afirma estar insatisfecho y muy insatisfecho (Tabla 11).

Dato de correlación que se mantiene en los tres municipios evaluados. Si el alcalde es mal evaluado también lo son la clase política municipal y viceversa; incluso dicha relación se mantiene con otros estudios realizados sobre felicidad urbana (Muñoz, 2018; 2019a; 2019b). 


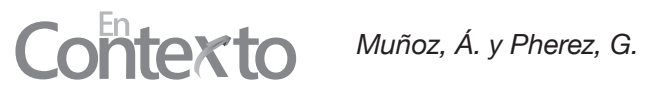

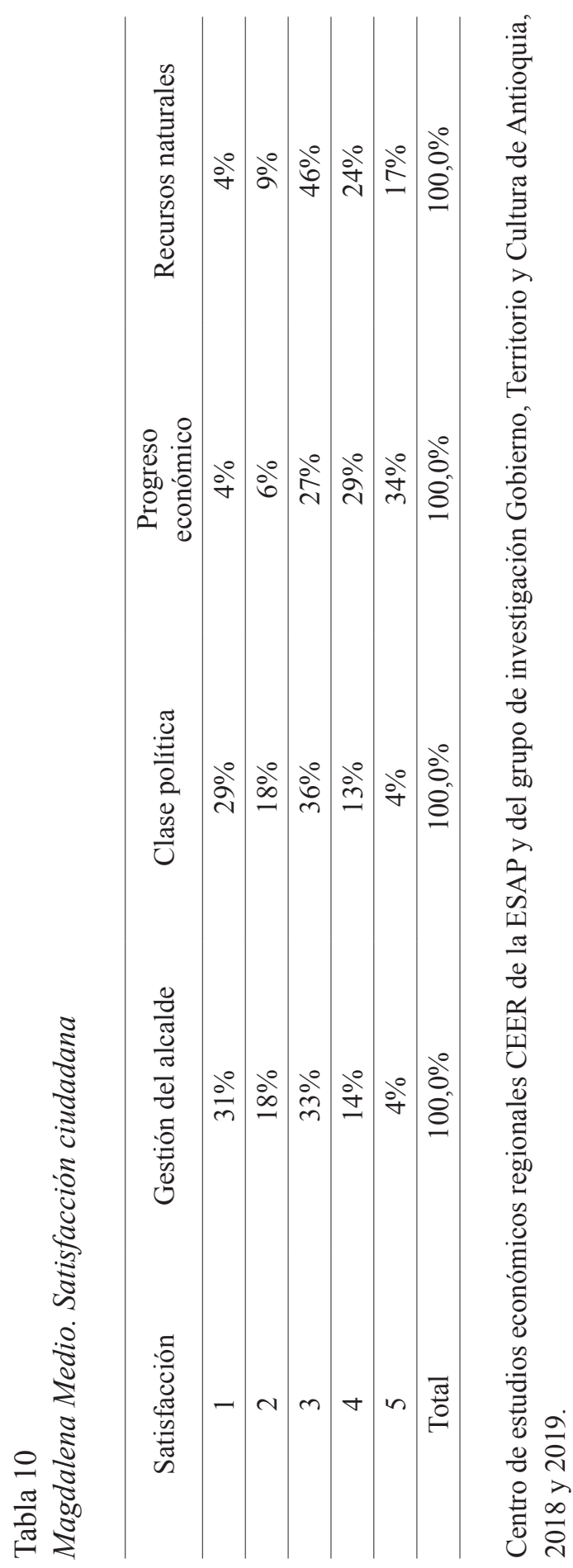


En Puerto Berrío, el 19\% de los estudiantes de undécimo grado afirma estar satisfecho y muy satisfecho con la gestión del alcalde, y el $22 \%$ con la clase política de su municipio. Es decir, más del 78\% de los adolescentes de grado 11 manifiesta abiertamente estar regularmente satisfecho y muy insatisfecho con la gestión del alcalde y con la clase política (Tabla 11). 
Contex to Muñoz, A. A Pherez, $G$.

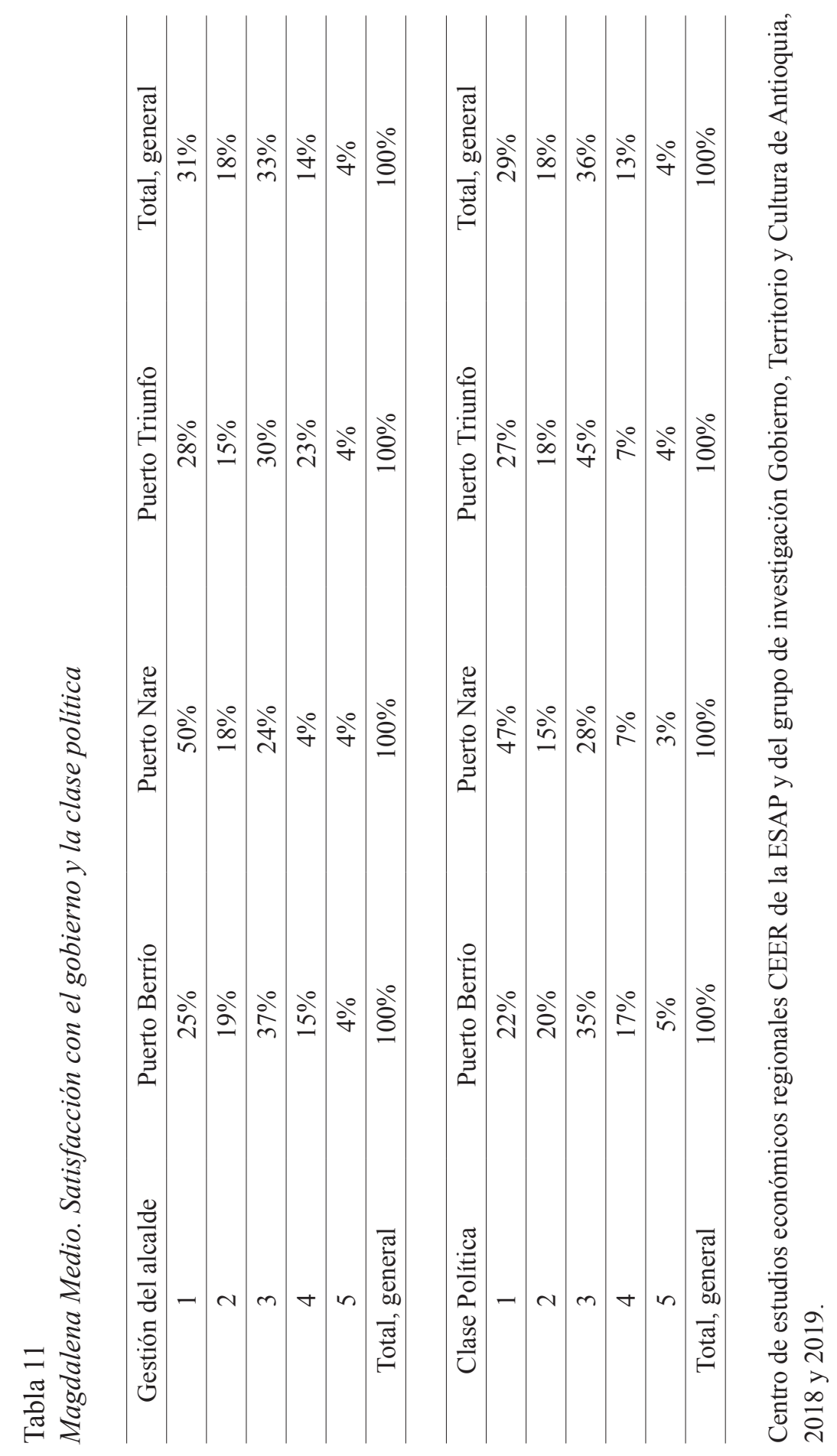


En Puerto Triunfo, el 27\% de los adolescentes de undécimo grado manifiesta estar satisfecho y muy satisfecho con la gestión del alcalde; de igual manera, el $11 \%$ lo manifiesta con la clase política del municipio. Por el contrario, el $73 \%$ de los adolescentes de grado 11 afirma estar muy regularmente satisfecho con la gestión del alcalde; de igual manera, el $89 \%$ con la clase política local. 
Contex to Muñoz, A. Y. Pherez, $G$.

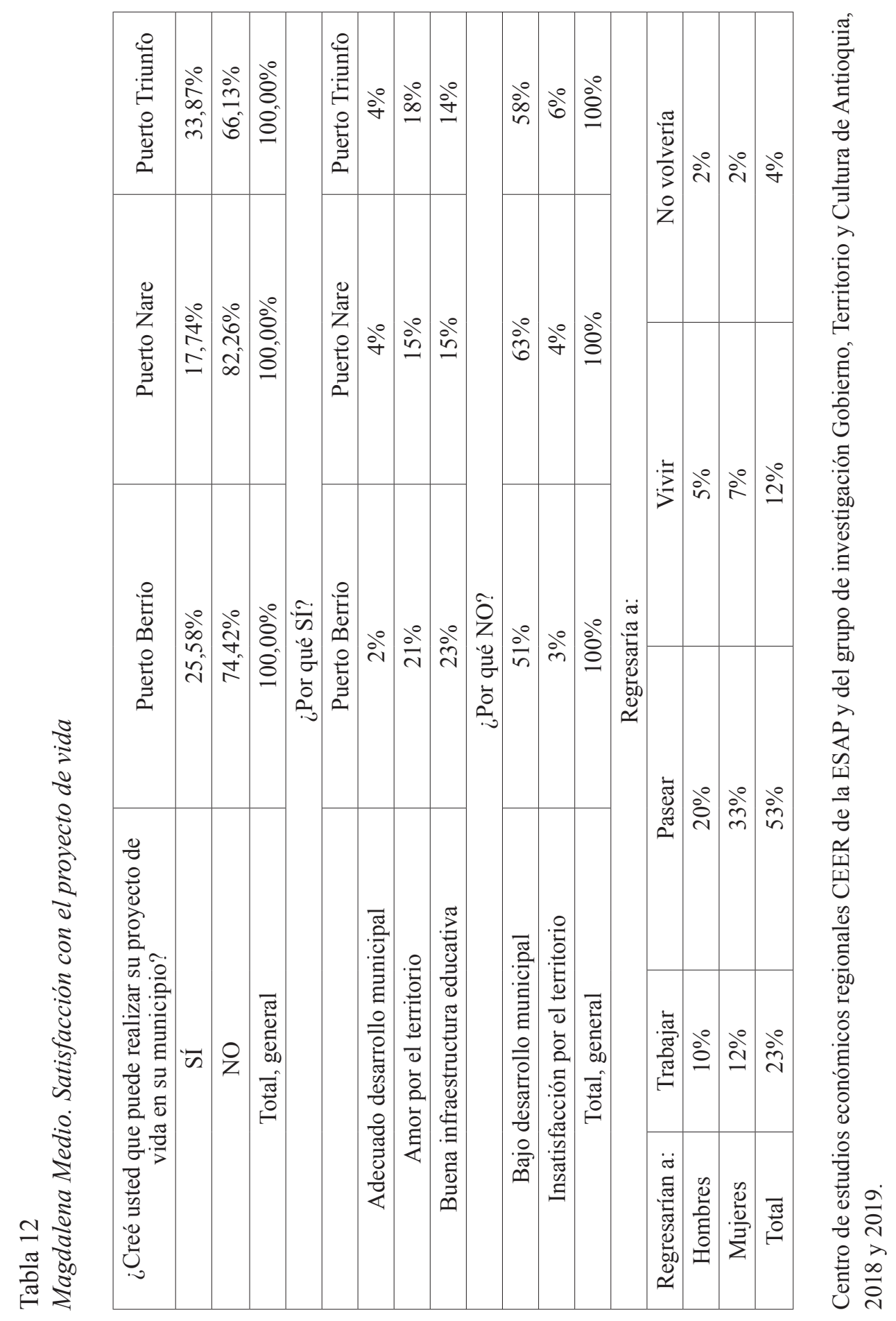


En cuanto al progreso económico de la región, llama la atención que el 63\% de los adolescentes de grado 11 del Magdalena Medio se encuentra satisfecho y muy satisfecho con el progreso económico de sus municipios; así mismo, el $41 \%$ de los estudiantes está satisfecho y muy satisfecho con los recursos naturales de sus territorios. Pero, ¿qué tan satisfechos están los adolescentes talento del Magdalena Medio con su proyecto de vida en la región?

Según la Tabla 12, más del $66,13 \%$ de los jóvenes adolescentes no cree poder realizar su proyecto de vida en su municipalidad, principalmente los estudiantes de Puerto Nare. Según una entrevista focal realizada en este, la principal razón que tienen los jóvenes para migrar a otros lugares es el bajo desarrollo municipal; si bien ellos aman el municipio, sus localidades no ofrecen futuro. El 89\% de los adolescentes bachilleres del Magdalena Medio afirma dejar sus municipios para poder lograr su autorrealización. De ellos, el 53\% regresaría a pasear, el 4\% no volvería. El 35\% regresaría a vivir y a trabajar (Tabla 12). Es decir, el Magdalena Medio corre el riesgo de perder el $65 \%$ de los talentos que forma por más de 16 años.

Es decir, el Magdalena Medio por su bajo desarrollo económico corre el riesgo de perder el $65 \%$ de su población bachiller talentosa. A pesar de que el $63 \%$ de los adolescentes de grado 11 afirmó estar satisfecho y muy satisfecho con el progreso económico de sus municipios (Tabla 11). El 65\% no ve a futuro un crecimiento económico que sea capaz de hacer realidad sus anhelos de autorrealización; no ven su futuro en sus territorios. Incluso en entrevista focal en el municipio de Puerto Nare, afirman que la peor amenaza que tienen sus municipios es la explotación minera, así como las enfermedades físicas y los problemas sociales de seguridad que genera la actividad minera.

Según entrevista focal realizada en Puerto Nare, el 47\% de los adolescentes no está satisfecho con la seguridad en las zonas del Magdalena Medio en las que vive, el $79 \%$ no cree mucho en las acciones de seguridad de la policía y el $80 \%$ no cree en la calidad de sus gobiernos municipales. Es decir, el Magdalena Medio parece perder institucionalidad democrática, transparencia en sus acciones, en otras palabras, sus valores públicos fundamentales. En oferta de servicios sociales como bibliotecas, museos, gimnasios a espacio abierto, los jóvenes-adolescentes afirman estar regularmente satisfechos con sus servicios y muy insatisfechos en más de un $70 \%$.

En conclusión, la administración pública local del Magdalena Medio debe mejorar la calidad de los gobiernos locales, para ello podría motivar el 


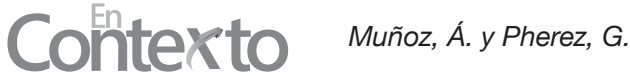

crecimiento económico por vías distintas a la explotación minera. Aprovechar, por ejemplo, el $41,6 \%$ del tiempo libre en ocio que tienen los adolescentes convirtiéndolos en ocio creativo, a través de lúdicas de emprendimiento. En otras palabras, aprovechando la capacidad natural de los adolescentes en ser creativos e innovadores o fomentando el estudio de un segundo idioma que sirva al fortalecimiento del servicio de atención a turistas extranjeros que visitan el territorio.

\section{Conclusiones}

Las Provincias de Cartama, San Juan, Aguas y el Magdalena Medio disfrutan de bienes y servicios básicos domiciliarios, poseen buena infraestructura de ciudad; sin embargo, no logran retener sus talentos bachilleres, más del $60 \%$ de los adolescentes desea migrar a buscar futuro a otros lugares. Más del 90\% de los jóvenes-adolescentes afirma sentirse feliz viviendo en sus municipios, pero cuando se les pregunta por la realización de sus proyectos de vida no se imaginan su futuro viviendo allí. No ven en sus Provincias su autorrealización. El Magdalena Medio, según la Tabla 1, es el territorio con menor oferta de espacios en servicios culturales, lo que demanda especial atención a la administración municipal. Y si bien los demás municipios de las PAP si poseen buenos espacios culturales, los jóvenes adolescentes poco los usan, menos del $10 \%$ dedica su tiempo libre al ocio creativo, al cultivo del yo cultural, más civilizado y social. De allí que se recomiende a todos los municipios estudiados la creación de programas públicos que sirvan al aprovechamiento de los espacios sociales y culturales: teatros, museos, parques culturales, casas de la cultura e Instituciones de Educación Superior para el empoderamiento de todos y cada uno de sus adolescentes talentosos.

El logro de una mayor equidad social es posible de alcanzar, si todas las fuerzas políticas y sociales trabajan juntas en el bienestar de todos, en la cohesión social para el bienestar en calidad de vida; lo que solo puede ser posible a través del fomento de la cultura, tal y como ya lo había afirmado Ottone (2009). Una cultura que eduque a la población en la sensibilidad del bien común, del logro de la felicidad general; una educación ciudadana que sirva al equilibrio de las fuerzas del poder político, económico, jurídico, es decir, que sirva al empoderamiento ciudadano.

Dado que más del 40\% de los jóvenes-adolescentes dedican su tiempo libre a actividades de ocio no creativo como ver televisión, chatear por internet, dormir, salir con amigos, tomar licor, escuchar música, jugar cartas o domino o 
balón pie, salir de compras a centros comerciales y estar con la pareja. Dichos tiempos de ocio, aunque necesarios, no forman en el talento de la capacidad reflexiva, en la sensibilidad de los sentidos, en el logro futuro de las metas de autorrealización. De allí que a través de programas de gobierno o de políticas públicas que impulsen las actividades creativas en jóvenes-adolescentes en talleres de literatura, teatro y artes escénicas, idiomas, poesía, pintura artística, piano, guitarra y participación ciudadana; sirvan al fortalecimiento de los talentos de la persona y al desarrollo económico municipal.

El ocio creativo como estrategia de las administraciones de gobierno sirve al fortalecimiento del altruismo comunitario (Camps y Giner, 2014); es la mejor manera de acceder al otro con respeto e inclusión, de fortalecer la resiliencia, la solidaridad, la capacidad de ver a los otros en un nosotros. Es en otras palabras, la herramienta de formación pública para estar bien y el buen vivir en sociedad, de lograr la autorrealización personal y la felicidad urbana a través del trabajo mancomunado.

\section{Referencias}

Acemoglu, D., y Robinson, J. (2012). Por qué fracasan los países. Los orígenes del poder, la prosperidad y la pobreza. Deusto.

Aristóteles. (2018). Ética Nicómaco. Alianza.

Beytía, P., y Calvo, E. (2011). ¿Cómo medir la felicidad?. Revista Claves de Politica Pública, 4, 1-10. DOI: http://dx.doi.org/10.2139/ssrn.2302809

Buitrago, F., y Duque, I. (2013). La economía naranja: una oportunidad infinita. BID, AGUILAR.

Camps, V., y Giner, S. (2014). Manual de civismo. Ariel.

Centro de Estudios Económicos Regionales. (CEER). (2018). Grupo de investigación de apoyo para el manejo de datos estadísticos al grupo de investigación consolidado en MINCIENCIAS de Colombia (COL 0034209). RES 163.450.264.

Chamorro, L. (2012). Esquemas asociativos como instrumento para la integración y el desarrollo regional. Departamento Nacional de Planeación, Subdirección de Ordenamiento y Desarrollo Territorial.

Congreso de la República de Colombia. (10 de enero de 1986). Acto Legislativo 01 de 1986. Por el cual se reforma la Constitución Política. Diario Oficial No. 37.304. 


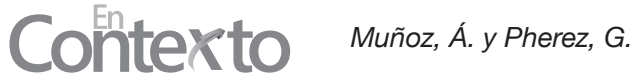

Congreso de la República. (26 de enero de 2006). Ley 1014. De fomento a la cultura del emprendimiento. 26 de enero de 2006. N. 46164.

Congreso de La República de Colombia. (29 de junio de 2011). Ley 1454 de 2011. Ley Orgánica de Ordenamiento Territorial LOOT. Diario Oficial No. 48.115.

Constitución Política de Colombia. (2012). Temis.

DANE. (2016). Primer diagnóstico de felicidad para Colombia. Presentación del director DNP Simón Gaviria Muñoz. DANE.

Dubet, F. (2017). Repensar la justicia social. Contra el mito de la igualdad de oportunidades. Siglo Veintiuno.

Dussel, E. (1998). Ética de la liberación. En la edad de la globalización y de la exclusión. Trotta

Gehl, J. (2010). Cities for People. Island Press.

Guisán, E. (2004). La ética mira a la izquierda. Anthropos.

Harari, Y. (2015). De animales a dioses (sapiens): breve historia de la humanidad. Debate.

Harari, Y. (2018). Homo Deus: breve historia del mañana. Debate.

InnovAntioquia. (2019). ;Innovar es la solución!. Secretaría de Productividad y Competitividad, Gobernación de Antioquia.

Jacobs, J. (2011). Muerte y vida de las grandes ciudades. Capitán Swin Libros.

Kaplan, R. (2017). La venganza de la geografía. RBA Libros.

Maslow, H. (2008). La personalidad creadora. Kairos, S.A.

McClelland, D. (1989). Estudio de la motivación humana. Narcea.

Mill, J. (2005). Sobre la Libertad. Alianza Editorial.

Muñoz, Á. (2018). Índices de Felicidad Urbana. ¿Son felices los jóvenes y adolescentes de grado 11 y último semestre universitario en Antioquia, Eje Cafetero, Santanderes y Quibdó?. Escuela Superior de Administración Pública. Dossier de Investigación.

Muñoz, Á. (2019a). Felicidad urbana. Área metropolitana del Valle de Aburrá. Revista En-Contexto, 7(11), 113-147.

Muñoz, Á. (2019b). Felicidad urbana en el Eje Cafetero. Revista de Antropología 
y Sociología: Virajes, 21(1), 197-228.

Muñoz, Á. (2019c). Descubriendo la economía. ¿Cómo lograr crecimiento y bienestar en economías locales?. Escuela Superior de Administración Pública, Facultad de Investigaciones.

Muñoz, Á., y Quintero, H. (2020). Las utopías del bienestar general. De la idea de ciudad de Thomas More a Yuval Harari. Reflexión Política, 22(44), 135-145.

Muñoz, Á., y Martínez, L. (2020). Emprendimiento social y felicidad urbana. Revista SUMMA, 2(1), 127-169.

Muñoz, Á., Vélez, R., Torres, D., Mesa, F., y Mayor, P. (2020). Modelo de política pública ambiental. Una forma de control fiscal y social. Contraloría General de Antioquia.

Nussbaum, M. (2010). Sin fines de lucro. Por qué la democracia necesita de las humanidades. Katz Editores.

Nussbaum, M., y Sen, A. (1998). La Calidad de Vida. Fondo de la Cultura Económica.

Ottone, E. (2009). Bienestar y estar bien. Un enfoque renovado de la cohesión social en América Latina. En A. Bárcena y N. Serra (Ed.), Reformas para la cohesión social en América Latina editado. Panorama antes de la crisis. CEPAL y Naciones Unidas.

Plan de Desarrollo de Medellín. (2016). Medellín cuenta con vos 2016-2019. Alcaldía de Medellín, Secretaria de Planeación Municipal.

Plan Nacional de Desarrollo 2018-2022. (2019). Pacto por Colombia, pacto por la equidad. Departamento Nacional de Planeación DNP, Presidencia de la República de Colombia.

Prieto, E. (2017). La fuerza de la asociatividad. El Metropolitano del Valle de Aburrá.https://www.metropol.gov.co/Paginas/Noticias/elmetropolitanoeditorial/la-fuerza-de-la-asociatividad.aspx Redacción. (03 de marzo de 2017). En Medellín así es la experiencia ciudadana de felicidad sentida. El Mundo. https://www.elmundo.com/noticia/En-Medellin-asi-es-laexperiencia-ciudadana-de-felicidad-sentida/48761

Resolución. (A/RES/65/309). Naciones Unidas. Asamblea General. Distrito General 25 de agosto de 2011. Sexagésimo quinto período de sesiones: Tema 13 del programa. https://www.un.org/en/ga/search/view_doc. asp?symbol $=\mathrm{A} / \mathrm{RES} / 65 / 309 \&$ Lang $=\mathrm{S}$ 


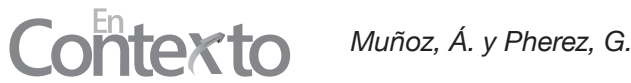

Resolución. (A/RES/66/281). Naciones Unidas. Asamblea General. Distrito General 12 de julio de 2012. Sexagésimo sexto período de sesiones: Tema 14 del programa. https://undocs.org/pdf?symbol=es/A/RES/66/281

Rey, G. (25 de julio de 2015). La felicidad si se puede medir. Portafolio. https:// www.portafolio.co/economia/finanzas/felicidad-medir-41202

Senado de la República de Colombia. (1994). Ley 152 de 1994. Por la cual se establece la Ley Orgánica del Plan de Desarrollo. Diario Oficial No. 41.450 .

Smith, A. (1997). Teoría de los sentimientos morales. Alianza Editorial.

Stiglitz, J., Sen, A., y Fitoussi J. (2015). Informe de la comisión sobre la medición del desarrollo económico y del progreso social. Síntesis y recomendaciones. CMPEPS.

Troyer, J. (Ed.). (2003). The classical utilitarians: Bentham and Mill. Hackett Publishing.

Zapata, O. (2017). Las provincias y las áreas metropolitanas en Colombia: potencias para la integración y el desarrollo regional. Revista de Políticas Públicas, 10(2), 1-32.

\section{Para citar este artículo:}

Muñoz, Á. y Pherez, G. (2020). El proyecto de vida y la retención de jóvenes talento en algunas provincias antioqueñas. En-Contexto, 8(13), 227-278. 